\title{
Education, Growth, and Redistribution in the Presence of Capital Flight*
}

\author{
Debajyoti Chakrabarty \\ University of Sydney
}

\author{
Areendam Chanda \\ Louisiana State University
}

Chetan Ghate ${ }^{\dagger}$

Indian Statistical Institute (New Delhi)

March 2006

\begin{abstract}
The conventional wisdom in the literature on capital controls and growth argues that capital controls increase the ability of a government to tax capitalists which proves detrimental for growth. To address this issue, we construct an OLG model to study the effect of capital controls on human capital investments and the incidence of redistributive taxation in a growing economy. We argue that the conventional wisdom linking higher capital controls to lower growth is reproduced only when an economy is sufficiently developed. For under-developed countries, higher capital controls can induce balanced growth, and the wisdom does not apply. When the model is augmented with a subsistence sector, we show that if workers are sufficiently poor, then workers do not invest in human capital. Hence, a modern sector does not exist. Higher capital controls however makes it feasible for a modern sector to exist by lowering the threshold income level required by workers to invest in human capital. Our results are consistent with recent evidence which show that, while financial liberalizations are associated with significant increases in growth, the effect is larger for countries with high education levels. Our results are also consistent with empirical evidence that argues that liberalizing the capital account positively affects growth only after a country has achieved a certain degree of economic development.
\end{abstract}

JEL Classification Codes: F21, D33, E62, O19, O40.

Keywords: Capital Flight, Economic Growth, Human Capital, Income Distribution, International Linkages to Development, Long Term Capital Movements, Optimal Taxation.

\section{Introduction}

Capital flight - from poor to rich countries - plagues many developing economies. In particular, capital flight tends to be more pronounced in countries mired in poverty traps with relative large inequalities

${ }^{*}$ This paper has benefitted from comments at the 2005 Meetings of the Association of Public Economic Theory Conference in Marseilles, the 2005 ACE Meetings in Melbourne, the Fifth (2005) Model and Methods Conference at ISI Kolkata, and departmental seminars at the University of Sydney, the University of New South Wales, and JNU - Delhi. We would like to thank Lutz Hendricks, Laura Alfaro and Peter Rangazas for useful comments. Debajyoti Chakrabarty would like to acknowledge financial support from the University of Sydney SESQUI Grant No. U3139.

${ }^{\dagger}$ Corresponding Author: Chetan Ghate, Planning Unit, Indian Statistical Institute - Delhi Center, 7 S.J.S Sansanwal Marg, New Delhi - 110016, India. Tel: 91-11-4149-3938. Fax: 91-11-4149-3981. E-mail: cghate@isid.ac.in. 
and low human capital investments. Collier et al. (2004) present evidence on capital flight for 30 under-developed countries over 1980-1998 and find that the average country in this sample has a flight ratio of $13 \%{ }^{1}$ Collier et al. (2004) show that countries in Sub-Saharan Africa have the highest capital flight ratios with $35 \%$ of private wealth held abroad. In comparison, average capital flight ratios in Latin American and South Asia are less but still significant (around $10 \%$ of private wealth). Further, Collier et al. (2001) find that in the regions around the world where capital flight is most severe, capital flight can lead to a major reduction in the real capital stock per worker leading to adverse effects on long run economic performance. ${ }^{2}$

Despite capital flight being widespread in under-developed countries, this phenomenon has received little attention in the political economy of growth literature. This paper attempts to fill this gap. In particular, we explore the long term growth implications of physical capital flight by examining how 1) capital flight affects the incidence of redistributive taxation, and 2) how capital flight affects human capital investments. Our contribution to the literature is to examine capital flight in a growth model with two factors of production: physical capital and human capital. To date, most of the literature has focussed on the impact of capital flight on a single accumulable factor - physical capital. We argue that the conventional wisdom - linking higher capital controls to lower growth - is reproduced only when an economy is sufficiently developed. For under-developed economies, capital controls can induce balanced growth. Therefore, for under-developed countries, the conventional wisdom linking higher capital controls to lower growth does not apply.

To capture the main elements of the interplay between capital flight, redistribution and growth, we model an OLG economy populated by dynastic agents who have access either to physical capital or human capital. Owners of physical capital have two alternative investment possibilities - investing at home or abroad. Investments abroad provide a secure return while investments at home are subject to redistributive taxation through a tax on capital income. We examine the optimal degree of taxation under these circumstances and the optimal degree of capital flight. Later, we augment the model by

\footnotetext{
${ }^{1}$ Collier et al. (2004) define capital flight as the ratio of the stock of flight capital to the stock of private wealth.Outwards capital flows are computed using the residual method and augmented with measures of export underinvoicing and import over-invoicing.

${ }^{2}$ Capital outflows from poor to rich countries is consistent with a neo-classical framework. For instance, Caselli and Feyrer (2005) argue that once the returns to capital are appropriately measured, current capital allocations across the world are already near their optimal levels. Any further reallocation from developed economies to developing economies only leads to minor and concentrated output gains. This suggests that if one adds restrictions to capital flows and risk factors, then capital should flow from poorer to richer countries, as the world capital return will exceed the domestic return in a developing economy.
} 
allowing workers to invest in human capital as well as in subsistence production. We show that if the income of workers is sufficiently low, the entire endowment of workers is invested in subsistence production, and none in human capital. As a result, the capitalists invest their entire endowment abroad. This implies that the modern sector in the economy does not exist. We then derive a threshold on worker endowments above which a modern sector exists, and below which, workers simply invest in the subsistence sector. We characterize the optimal tax rates under subsistence production. Importantly, we show that as worker income grows over time, the subsistence sector vanishes, and the growth rate of human capital converges to the model without subsistence production.

The conventional wisdom in this literature says that reducing capital controls will curb the ability of the government to tax capitalists and therefore prove beneficial for growth. We argue that it is indeed true but only when an economy is sufficiently developed and is able to sustain a balanced growth equilibrium in steady state. This result is consistent with a large literature on capital mobility and economic performance which suggests that an open capital account positively affects growth only after a country has achieved a certain degree of economic development (Edwards, 2000). When an economy is underdeveloped and experiencing capital flight, we show that this argument does not apply. Higher capital controls relax the constraint for the existence of balanced growth in steady state equilibrium. We also argue that higher capital controls in this environment can prevent excessive capital flight and help an economy develop its modern sector.

This paper is structured as follows. Next, we briefly discuss the related literature. In section 2 , the model is setup and the optimal decisions of the two groups are solved for. The dynamics are characterized in section 3. Section 4 extends the model to include the possibility of subsistence production and the emergence of development traps. Section 5 concludes.

\section{$1.1 \quad$ Related Literature}

Our research is motivated by a large corpus of literature studying the association between inequality and growth. This literature examines the effect of income distribution on economic growth by examining the impact of redistributive politics on physical capital investment and/or human capital investment. Extensions of this literature incorporate roles for redistribution, public financing of education, capital market imperfections, and non convexities in technologies. Beginning with Perotti (1996), the empirical literature has failed to find a robust relationship between inequality and consequent redistribution despite theoretical models continuing to rely on this link. ${ }^{3}$ However, these

\footnotetext{
${ }^{3}$ For a recent survey of this literature see Glaeser (2005).
} 
models either tend to assume closed economies (Alesina and Rodrik (1994)) or avoid physical capital altogether (Saint Paul (1993)). While Galor and Moav (2004) incorporate physical capital and human capital accumulation in the process of economic growth, their analysis is also based on a closed economy framework. It does not take much to realize that once one allows the possibility of capital flight, then even workers who do not earn a return from physical capital will not necessarily want to tax at high rates since that would encourage further capital flight and reduce their own wages. Therefore the obvious link between inequality and redistribution breaks down. ${ }^{4}$ This suggests the extent of redistribution depends not just on the degree of inequality but also the openness of the economy to capital flows.

While the literature on the interaction between physical capital and human capital and their effects on economic growth is large, there are a few papers that are directly related to our work. Galor and Moav (2004) examine the relative importance of physical capital and human capital at different stages of economic development and looks at implications of inequality on economic growth. They show that in the initial stages of development, physical capital is more important and therefore inequality is beneficial. In later stages as human capital becomes more important, inequality is less beneficial. ${ }^{5}$

While it is not our attempt here to rewrite the various stages of development after incorporating capital flight, it is still useful to consider the implications of capital flight on the stages of development. Our theoretical results suggest that a less developed economy can actually end in either poverty traps with absolutely no human capital accumulation or even growth traps with sustained increases in inequality and a declining human capital to physical capital ratio with permanent capital flight. We find that capital controls can be beneficial to under-developed countries for two reasons. First, they keep the level of domestic investment high (and reduce capital flight) which leads to higher domestic wages, domestic income, and investment in human capital. Second, the endogenous threshold required to jump to a balanced growth path is lowered with higher capital controls. This makes it easier for an under-developed economy to transition to a 'high' growth path. However, once on a high growth path, we show that the effect of capital controls is detrimental to the growth in capital and education. This

\footnotetext{
${ }^{4}$ See Mourmouras and Rangazas (2005) for estimates on the extent to which financial openness places an upper bound on domestic taxation for developing countries. Quadrini (2005) finds that the transition from a regime of capital autarky to a regime of free mobility leads to a decrease in the long term tax rate on capital of $13 \%$, leading to a welfare increase of $1 \%$ in European countries. Like Caselli and Freyer (2005), Gournichas and Jeanne (2003) support the consensus view in the literature that the welfare effects of financial opening are not large. In Gournichas and Jeanne (2003) however, the steady state is independent of whether the economy is open or closed. Our framework differs from these papers as financial opening affects both the steady state as well as the transition path.

${ }^{5}$ Alfaro and Kanzuk (2001) consider an overlapping generations model in which agents vote on whether to open or close an economy to international capital flows. They derive conditions under which an economy can cycle between open and closed, which is consistent with economies in an 'intermediate' stage of development.
} 
is consistent with recent evidence in Bekaert et al. (2001) who show that while financial liberalizations are associated with significant increases in economic growth, the effect is larger for countries with high education levels. In particular, Bekaert et al. (2001) show that the coefficient on the liberalization indicator is three times larger for countries with above median education levels. These results suggest that policy makers should not expect a significant growth impact from financial market liberalization if the country's education level is lower than the median of the 30 emerging market economies in their sample (Bekaert et al (2001, p. 492)).

Our work is also related to Bourguignion and Verdier (2000b) and Viaene and Zilcha (2002a,b). For instance, Bourguignion and Verdier (2000b) examine the willingness of capital owners to fund public education. Their work, which is a part of a larger literature on the transition from oligarchies to democracies, examines the impact of capital flight on the public funding of education. While in a closed economy, oligarchs (who are assumed to be capitalists) may choose to subsidize education, once the economy opens up to capital flight, the same incentive disappears and hence international financial liberalization is bad for education. In our paper this possibility of a development trap where there are physical capital outflows and zero human capital emerges as a special case. Moreover, we are more concerned with the incentives of the owners of human capital to redistribute in the presence of international capital flows. Hence, the two papers are complementary. ${ }^{6}$

Viaene and Zilcha (2002b) examine the role of government intervention in raising human capital investments in a two country model. Their work focuses on the issue of competition between governments in trying to garner a larger share of output and the role of public education spending in the final outcome. However, Viaene and Zilcha (2002a) - which is more closely related to our work - allows for heterogeneity in income across agents. Viaene and Zilcha (2002a) find that capital market integration does not affect the long run growth rate of an economy (when compared to the autarkic case), and that capital market integration is always preferred by altruistic households even if later generations lose and integration reduces income inequality in the country that experiences outflows. These results are different from ours. In addition, the theoretical framework in Viaene and Zilcha (2002a) and our framework is quite different: we do not assume public provision of education, while income distribution in our framework is represented in terms of its functional distribution with different groups acting strategically. In contrast, Viaene and Zilcha (2002a) assume a continuum of agents.

\footnotetext{
${ }^{6}$ More recently, Bourguignon and Verdier (2005) use a Ricardo-Viner framework to show that when a small open economy opens up to trade, the effects on education reduce the wage skill gap and makes education privately less profitable for those who can afford it. Trade may also lessen the liquidity constraint of poor unskilled workers which leads to more investment in human capital being undertaken.
} 


\section{The Model}

The aggregate production function of the economy in period $t$ is given by

$$
Y_{t}=A K_{t}^{\gamma} H_{t}^{1-\gamma}
$$

where $Y_{t}$ denotes output, $H_{t}$ and $K_{t}$ denote the aggregate amounts of human capital and physical capital respectively, $A>0$ denotes a technological shift parameter ${ }^{7}$, and $\gamma \in(0,1)$. The economy consists of two types of agents called capitalists - indexed by $K$ - and workers - indexed by $W$, of equal measure. The capitalists provide physical capital whereas the workers supply the human capital in the production process.

There are competitive markets for both physical and human capital. The wage rate and rental rate are

$$
w_{t}=(1-\gamma) \frac{Y_{t}}{H_{t}}
$$

and

$$
r_{t}=\gamma \frac{Y_{t}}{K_{t}}
$$

respectively.

In each time period $t-1$, where $t=1,2, \ldots \infty$, a new generation of agents are born who live for two periods at the end of which they are replaced by an offspring of their type. Each agent is born with a type of endowment. The capitalists are born with an endowment of capital goods, $b_{t}^{K}$. Workers are born with an endowment, $b_{t}^{W}$, which they invest entirely in human capital, $e_{t}$ : i.e., $b_{t}^{W}=e_{t}$. Human capital in period $t$ depends on the level of education according to

$$
H_{t}=e_{t-1}^{\theta}
$$

where $\theta \in[0,1]$. We assume that both workers and capitalists become economically active in the second period of their life: they only care about second period consumption and make an inter-vivos transfer to their offspring. ${ }^{8}$

Workers have the political power to extract rents from the capitalists in the form of a tax on capital income. In particular, in period $t-1$, the workers announce a tax rate, $\tau_{t}$, to be imposed on capital income in period $t$. Based on the announcement of the tax rate at the end of period $t-1$,

\footnotetext{
${ }^{7}$ Alternatively one can think of " $A$ " as a parameter which captures the level of development of an economy in terms of its state of legal institutions or the state of development of its financial markets.

${ }^{8}$ For the rest of the paper we will use the terms, bequests and endowments interchangeably to refer to these transfers.
} 
the capitalists decide how much of their capital stock to invest at home and abroad. ${ }^{9}$ Let $\bar{r}$ denote the world interest rate where $\bar{r}>1$ which the capitalists take as given. We assume that investment abroad is costly for the capitalists depending on the capital control regime existing in the economy. For each unit of capital invested abroad, the capitalists get a return of $(\bar{r}-\phi)$. The parameter, $\phi$, captures in a straightforward way the extent of capital controls in an economy. In particular, $\phi=0$, corresponds to an economy without capital controls, while, $\phi=\bar{r}$, corresponds to a closed economy. $\phi$ here simply reflects a deadweight loss that owners of physical capital need to bear to move their capital illegally out of the country. ${ }^{10}$

Our setup implies that the post - tax income of the workers and capitalists is given by

$$
y_{t}^{W}=w_{t} H_{t}+\tau_{t} r_{t} K_{t}=\left[(1-\gamma)+\tau_{t} \gamma\right] A K_{t}^{\gamma} H_{t}^{1-\gamma},
$$

and

$$
\begin{aligned}
y_{t}^{K} & =\left(1-\tau_{t}\right) r_{t} K_{t}+(\bar{r}-\phi)\left(b_{t-1}^{K}-K_{t}\right) \\
& =\left(1-\tau_{t}\right) \gamma A K_{t}^{\gamma} H_{t}^{1-\gamma}+(\bar{r}-\phi)\left(b_{t-1}^{K}-K_{t}\right),
\end{aligned}
$$

respectively.

Before we characterize the optimal tax rate under capital flight, we address some of the assumptions that we have made in this setup: a) the worker-capitalist divide, b) workers choose the tax rate, and c) the human capital production function.

The worker-capitalist separation is standard in models of distributional conflict and growth . For example, Das and Ghate (2004) use a similar separation to study distributional conflict in a heterogenous agent model of growth and distribution. Aguiar, Amador, and Gopinath (2005) use a worker-capitalist setup to study the pro-cyclicality of tax policies in emerging markets. Similarly, Bourguignion and Verdier (2005, 2000a, 2000b) use a worker-capitalist setup to study the timing of political transitions. Note that in the current framework owners of physical capital are not allowed to invest in human capital and vice versa. This is not limiting: as long as one group derives income mainly from capital and another group from human capital, our results are qualitatively similar to a model in which agents derive income from both factors. ${ }^{11}$

\footnotetext{
${ }^{9}$ Since both workers and capitalists are economically inactive in the first period and only active in the second period, they only vote for second period taxes and not for the first period. Thus every generation gets to vote only once. Further, we abstract from commitment issues.

${ }^{10}$ This reflects our focus on "unrecorded" capital outflows. Note that Collier et al (2004) also measure capital flight as a residual rather than official measures of outflows.

${ }^{11}$ An alternate setup might utilize a variant of the existing OLG structure where the young working generation derive
} 
Secondly, consistent with the growth and distribution literature, we assume that the workers determine the tax rate in the economy. This assumption is consistent with political economy in dynamic models in which the median voter - defined as an agent that is poorer than the 'average agent' in terms of income or capital holdings - is the decisive voter. We therefore have in mind an under-developed economy in which the political parties converge to the preferred policies of the median voter who is a capital-poor agent.

Our third assumption concerns the human capital production function. In the current setup, the human capital production function follows Galor and Moav (2004, 2006) in terms of focusing exclusively on education expenditures. Recently, Manuelli and Seshadri (2005) have shown that if one incorporates human capital expenditures (i.e., both formal schooling and pre-schooling expenditures in nutrition, etc.) into human capital stock measurements, then large TFP gaps between countries disappear. ${ }^{12}$ We could also incorporate existing human capital into the education production function. However, what is important is that current investment in human capital be a positive function of current income. As long as this holds, the model would admit a less primitive form of the production structure. ${ }^{13}$

We now characterize the optimal tax rate set by workers and the resulting domestic investment undertaken by capitalists.

\subsection{The Optimal Tax Rate and Capital Flight}

The maximization problem faced by a worker born in period $t-1$ is given by

$$
\begin{aligned}
& \max U^{W}=\alpha \log c_{t}^{W}+(1-\alpha) \log b_{t}^{W}, \alpha \in(0,1) \\
& \text { subject to } c_{t}^{W}+b_{t}^{W} \leq y_{t}^{W}
\end{aligned}
$$

where $c_{t}^{W}, y_{t}^{W}$ denotes the consumption and income of the worker. The optimal decision rules for the worker are given by

$$
c_{t}^{W}=\alpha y_{t}^{W}
$$

income from human capital and form one voting group. The elder retired generation derive only interest income and hence might be viewed as "capitalists" and form another voting group. As long as the younger group has the median voter (possibly because of positive population growth), similar results would obtain. Alfaro and Kanzuck (2004) use an OLG setup although though they do not focus on human capital accumulation.

${ }^{12}$ Earlier studies like Bils and Klenow (2000) and Hall and Jones (1999) focussed on the length of years and not on the expenditure component.

${ }^{13}$ We also assume that capital outflows are not taxable. Again, this is driven by the empirical observation that capital flows out to escape taxation. Further making capital outflows taxable would make the entire model's results hinge on the assumed respective technologies of tax collection- an uninteresting proposition. 
and

$$
b_{t}^{W}=(1-\alpha) y_{t}^{W}
$$

Log utility implies that workers consume and bequeath a constant proportion of their income.

The capitalists also face a similar maximization problem as the worker. The only difference with respect to the workers is that capitalists bequeath an endowment of capital for their offspring (as opposed to education). A capitalist born in period $t-1$ solves the following problem:

$$
\begin{aligned}
& \max U^{K}=\alpha \log c_{t}^{K}+(1-\alpha) \log b_{t}^{K}, \alpha \in(0,1) \\
\text { subject to } & c_{t}^{K}+b_{t}^{K} \leq y_{t}^{K}
\end{aligned}
$$

where $c_{t}^{K}, y_{t}^{K}$ denotes the consumption and income of the capitalist. The optimal decision rules for the capitalists are given by

$$
c_{t}^{K}=\alpha y_{t}^{K}
$$

and

$$
b_{t}^{K}=(1-\alpha) y_{t}^{K}
$$

Like the worker, the decision rules imply that capitalists also consume and bequeath a constant proportion of their income. Note that as far as utility of an agent is concerned, any policy that maximizes the income of an agent also maximizes her utility. Given any capital income tax rate imposed by the workers, the capitalist's behavior is summarized in the following lemma.

Lemma 1 Given any tax rate on capital income and domestic rental rate the capitalist will allocate investment home or abroad according to the following criterion:

$$
K_{t}= \begin{cases}0 & \text { if } r_{t}\left(1-\tau_{t}\right)<\bar{r}-\phi \\ {\left[\frac{\left(1-\tau_{t}\right) \gamma A}{\bar{r}-\phi}\right]^{\frac{1}{1-\gamma}} H_{t}} & \text { if } r_{t}\left(1-\tau_{t}\right)=\bar{r}-\phi \\ b_{t-1}^{K} & \text { if } r_{t}\left(1-\tau_{t}\right)>\bar{r}-\phi\end{cases}
$$

Proof: The capitalists will allocate their investment home or abroad such that their income is maximized. Maximizing equation (5) with respect to $K_{t}$ gives the expression above.

Lemma 1 characterizes the optimal investment rule by capitalists. Given the domestic return to capital, tax rate, and the world interest rate, the capitalist's entire endowment is invested abroad if $r_{t}\left(1-\tau_{t}\right)<\bar{r}-\phi$. This implies that there is complete capital flight, and no domestic investment. If $r_{t}\left(1-\tau_{t}\right)=\bar{r}-\phi$, part of the endowment of capitalists is invested abroad and part of it invested domestically. If $r_{t}\left(1-\tau_{t}\right)>\bar{r}-\phi$, there is no capital flight, as the domestic after tax return to capital exceeds the world interest rate. 
Given the capitalist's decision rule, we can characterize the worker's optimal tax rate. The marginal product of capital schedule is shown in Figure 1. At any time period $t$, the pre-tax rental rate is a decreasing function of the domestic investment, $K_{t}$. The maximum possible domestic investment is the endowment of the capitalist, $b_{t-1}^{K}$. The rental rate of capital at this level of investment is denoted as $\widehat{r}_{t}$. It will turn out later that $\widehat{r}_{t}$ plays a crucial role in the optimal tax behavior of the workers. Equations (3) and (4) imply

$$
\widehat{r}_{t}=\gamma A\left(\frac{e_{t-1}^{\theta}}{b_{t-1}^{K}}\right)^{1-\gamma} .
$$

Note that the entire $r_{t}$ schedule and $\widehat{r}_{t}$ shifts upwards as the level of human capital increases (see Figure 1). The next proposition characterizes the optimal tax rate for the workers.

\section{INSERT FiguRE 1 HeRE.}

Proposition 1 In equilibrium, the workers set a tax rate such that the capitalist is indifferent between investing at home or abroad. The optimal tax rate is given by:

$$
\tau_{t}= \begin{cases}0 & \text { if } \widehat{r}_{t} \leq \bar{r}-\phi \\ 1-\frac{\bar{r}-\phi}{\widehat{r}_{t}} & \text { if } \widehat{r}_{t}>\bar{r}-\phi\end{cases}
$$

Proof: The capitalists get a return of $\bar{r}-\phi$ from foreign investment. Suppose $\widehat{r}_{t}<\bar{r}-\phi$. From (6), the domestic supply of capital is given by $K_{t}=\left[\frac{\left(1-\tau_{t}\right) \gamma A}{\bar{r}-\phi}\right]^{\frac{1}{1-\gamma}} H_{t}$. The income of the worker is

$$
y_{t}^{W}=\left[(1-\gamma)+\tau_{t} \gamma\right]\left[\frac{\left(1-\tau_{t}\right) \gamma}{\bar{r}-\phi}\right]^{\frac{\gamma}{1-\gamma}} A^{\frac{1}{1-\gamma}} H_{t}
$$

The tax rate that maximizes $\left[(1-\gamma)+\tau_{t} \gamma\right]\left[\left(1-\tau_{t}\right) \gamma\right]^{\frac{\gamma}{1-\gamma}}$ will also maximize the worker's income. Maximizing the expression, $\left[(1-\gamma)+\tau_{t} \gamma\right]\left[\left(1-\tau_{t}\right) \gamma\right]^{\frac{\gamma}{1-\gamma}}$, with respect to $\tau$ implies that the optimal tax rate is zero. If $\widehat{r}_{t}>\bar{r}-\phi$, the workers will set a tax rate up to a point where the capitalist is indifferent between investing at home or abroad. Hence, the tax rate that maximizes a worker's income is given by the following condition:

$$
\widehat{r}_{t}\left(1-\tau_{t}\right)=\bar{r}-\phi
$$

Note that Proposition 1 implies that the equilibrium tax rate is given by,

$$
\tau_{t}=\max \left\{0,1-\frac{\bar{r}-\phi}{\widehat{r_{t}}}\right\}
$$


with domestic investment given by,

$$
K_{t}=\left\{\begin{array}{ll}
{\left[\frac{\gamma A}{\bar{r}-\phi}\right]^{\frac{1}{1-\gamma}} e_{t-1}^{\theta}} & \text { if } \widehat{r}_{t} \leq \bar{r}-\phi \\
b_{t-1}^{K} & \text { if } \widehat{r}_{t}>\bar{r}-\phi
\end{array} .\right.
$$

If $\widehat{r}_{t} \leq \bar{r}-\phi$, the optimal tax for the workers is 0 and we have an interior solution to the capitalist's allocation problem between domestic and foreign investment, i.e., maximization of equation (5) with respect to $K_{t}$. If $\widehat{r}_{t}>\bar{r}-\phi$, we get a corner solution: the workers tax the difference between $\widehat{r}_{t}$ and $\bar{r}-\phi$. Finally, we rule out the case that $\bar{r}-\phi=0$. If $\bar{r}-\phi=0$, then the capitalists have no other option apart from investing at home. Accordingly, workers simply tax capital income entirely, and the economy has zero capital stock from the next period onwards. Since this is an uninteresting case, we assume that, $\bar{r}-\phi>0 .{ }^{14}$

In the appendix, we show that the optimal tax rate characterized by Proposition 1 holds for any neo-classical technology that is constant returns to scale in $K$ and $H$. Hence, the optimal tax results and the dynamics that fellow - are robust to any neo-classical technology that exhibits constant returns to scale in the assumed factor inputs. This fully characterizes the tax rate and the composition of investment in equilibrium. ${ }^{15}$

Figure 2 summarizes the tax chosen by the workers and the resulting investment behavior of the capitalists. Figure 2a shows that the amount of capital flight in an interior equilibrium. In Figure 2a, the marginal product of capital schedule intersects the world interest rate $\bar{r}-\phi$ and keeps falling so that $\widehat{r}_{t}$ is less than $\bar{r}-\phi$. In this case the optimal tax for the workers is zero. The point of intersection between the $r_{t}$ schedule and $\bar{r}-\phi$ gives us the amount of domestic investment and capital flight.

In Figure $2 \mathrm{~b}$, the $r_{t}$ schedule is decreasing but $\widehat{r}_{t}$ exceeds the world interest rate, $\bar{r}-\phi$. In this case the workers will tax capital until the capitalists are just indifferent between investing at home or abroad. Ex-post, this implies $r_{t}\left(1-\tau_{t}\right)=\bar{r}-\phi$ and there is no capital flight. Note that Figure $2 \mathrm{~b}$ shows the optimal tax behavior of the worker in the case of a corner equilibrium.

\section{Insert Figure 2A AND 2B Here.}

\footnotetext{
${ }^{14}$ We later state a regularity condition to ensure that the capitalist's endowment doesn't converge to zero.

${ }^{15}$ If foreign and domestic capital are perfect substitutes - as in the current setup - then there will be no capital inflows when the domestic interest rate is low. This happens in the current framework when an interior solution with zero taxation obtains in equilibrium. When the domestic interest rate is high, a corner equilibrium obtains in which workers tax the capitalists to keep the capitalists just indifferent between investing domestically and investing abroad. Hence, allowing capital inflows does not change Proposition 1. To keep the model tractable, we therefore rule out capital inflows in the subsequent analysis.
} 


\section{The Dynamic Evolution of Education and Capital}

In this section, we characterize the transitional dynamics and the steady state behavior of the economy. We show that whether balanced growth obtains depends on whether $\theta=1$, or $\theta<1$, respectively. We also derive an endogenous threshold relating the technology parameter, " $A$ ", to the capital control parameter, $\phi$. The endogenous threshold determines whether the worker's income and human capital accumulation matches the growth in income of the capitalists and the accumulation of capital. Importantly, we show that capital controls can lead to a higher growth in education if the economy is at a lower level of development.

\section{$3.1 \quad \theta=1$}

We first consider the case where $\theta=1$. The capitalist's income in equilibrium is given by $y_{t}^{K}=$ $(\bar{r}-\phi) b_{t-1}^{K}$, irrespective of whether $\widehat{r}_{t}$ is less than or greater than $\bar{r}-\phi$. The capitalist's capital endowment grows at the rate

$$
g_{K}=\frac{b_{t}^{K}}{b_{t-1}^{K}}=(1-\alpha)(\bar{r}-\phi)
$$

The income of workers is given by,

$$
\begin{aligned}
y_{t}^{W} & =\left[(1-\gamma)+\tau_{t} \gamma\right] A K_{t}^{\gamma} H_{t}^{1-\gamma}=\left[(1-\gamma)+\tau_{t} \gamma\right] A K_{t}^{\gamma} e_{t-1}^{\theta(1-\gamma)} \\
& =\left[(1-\gamma)+\tau_{t} \gamma\right] A K_{t}^{\gamma} e_{t-1}^{\delta} .
\end{aligned}
$$

where $\delta=\theta(1-\gamma)$. From Proposition 1, the evolution of education is given by

$$
e_{t}=\left\{\begin{array}{c}
(1-\alpha)(1-\gamma)\left[\frac{\gamma}{\bar{r}-\phi}\right]^{\frac{\gamma}{1-\gamma}} A^{\frac{1}{1-\gamma}} e_{t-1}^{\theta} \text { if } \widehat{r}_{t} \leq \bar{r}-\phi \\
(1-\alpha)\left[(1-\gamma)+\tau_{t} \gamma\right] A\left(b_{t-1}^{K}\right)^{\gamma}\left(e_{t-1}\right)^{\delta} \text { if } \widehat{r}_{t}>\bar{r}-\phi
\end{array}\right.
$$

It is clear from equation (9) that the dynamics of the evolution of capital does not depend on the parameter $\theta$. However, the evolution of education given by equation (10) depends on the value of the parameter, $\theta$. To ensure that the capitalist's endowment grows over time, we require the regularity condition: $(1-\alpha)(\bar{r}-\phi)>1 .{ }^{16}$ This implies that the capitalist's endowment of capital grows at a constant rate if the economy does not have any capital controls in place.

Since $\theta=1$, from (10), the evolution of education is given by,

$$
e_{t}=\left\{\begin{array}{c}
(1-\alpha)(1-\gamma)\left[\frac{\gamma}{\bar{r}-\phi}\right]^{\frac{\gamma}{1-\gamma}} A^{\frac{1}{1-\gamma}} e_{t-1} \text { if } \widehat{r}_{t} \leq \bar{r}-\phi \\
(1-\alpha)\left[(1-\gamma)+\tau_{t} \gamma\right] A\left(b_{t-1}^{K}\right)^{\gamma}\left(e_{t-1}\right)^{1-\gamma} \text { if } \widehat{r}_{t}>\bar{r}-\phi
\end{array}\right.
$$

\footnotetext{
${ }^{16}$ We can also think of this as an upper bound on the extent of capital controls, i.e., $\phi \leq \bar{r}-(1-\alpha)^{-1}$.
} 
The next proposition summarizes the steady state equilibrium growth rate of education in comparison to the growth rate of capital.

Proposition 2 Let $g_{e}$ and $g_{K}$ denote the (gross) growth rates of education and capital, respectively. Define $\underline{A}(\phi)$ as

$$
\underline{A}(\phi)=\frac{\bar{r}-\phi}{(1-\gamma)^{1-\gamma} \gamma^{\gamma}}
$$

If $A \geq \underline{A}(\phi)$ there exists a unique balanced growth equilibrium where $g_{e}=g_{K}=(1-\alpha)(\bar{r}-\phi)$. If $A<\underline{A}(\phi)$ then in the steady state, $g_{K}>g_{e}$.

Proof: Define the critical value of the capital-education ratio that yields an interior solution as $\frac{\widehat{b^{K}}}{e}=\left(\frac{\gamma A}{\bar{r}-\phi}\right)^{\frac{1}{1-\gamma}}$. Note that if $\frac{b_{t}^{K}}{e} \leq \frac{\widehat{b^{K}}}{e}$, a corner solution obtains. For a corner equilibrium, from Proposition 1 and equation (11), we know that the growth rate of education is given by,

$$
\begin{aligned}
& g_{e}=\frac{e_{t}}{e_{t-1}}=(1-\alpha)\left[1-\frac{\bar{r}-\phi}{\gamma A\left(\frac{b_{t-1}^{K}}{e_{t-1}}\right)^{\gamma-1}} \gamma\right] A\left(\frac{b_{t-1}^{K}}{e_{t-1}}\right)^{\gamma} \\
& g_{e}=(1-\alpha)\left[A\left(\frac{b_{t-1}^{K}}{e_{t-1}}\right)^{\gamma}-(\bar{r}-\phi)\left(\frac{b_{t-1}^{K}}{e_{t-1}}\right)\right] .
\end{aligned}
$$

Note that $\arg \max g_{e}=\frac{\widehat{b^{K}}}{e}$. This implies that the maximum growth rate with a corner solution for, $g_{e}^{*}$, is given $b^{\left(\frac{b K}{e}\right)}$ :

$$
g_{e}^{*}=(1-\alpha)(1-\gamma) A^{\frac{1}{1-\gamma}}\left(\frac{\gamma}{\bar{r}-\phi}\right)^{\frac{\gamma}{1-\gamma}}
$$

Now we look at the case of an interior equilibrium. If $\frac{b_{t}^{K}}{e}>\frac{\widehat{b^{K}}}{e}$, equation (11) implies that the growth rate of education is given by, $g_{e}^{*}=(1-\alpha)(1-\gamma)\left[\frac{\gamma}{\bar{r}-\phi}\right]^{\frac{\gamma}{1-\gamma}} A^{\frac{1}{1-\gamma}}$. From equation (9), $g_{K}=(1-\alpha)(\bar{r}-\phi)$. Let $\underline{A}(\phi)$ be the level of technological parameter where this condition, $g_{e}^{*}=g_{K}$, holds with equality, i.e.,

$$
\underline{A}(\phi)=\frac{\bar{r}-\phi}{(1-\gamma)^{1-\gamma} \gamma^{\gamma}}
$$

In the steady state, if $A<\underline{A}(\phi), g_{e}<g_{K}$ : i.e., there will always be capital flight and the growth rate of education will be strictly less than the growth rate of capital. However, if $A \geq \underline{A}(\phi)$, there exists a unique $\left(\frac{b^{K}}{e}\right)$ ratio such that $g_{e}=g_{K}=(1-\alpha)(\bar{r}-\phi)$ : i.e., in the steady state, there will be no capital flight.

$$
g_{e}=\left\{\begin{array}{c}
(1-\alpha)\left[A\left(\frac{b_{t-1}^{K}}{e_{t-1}}\right)^{\gamma}-(\bar{r}-\phi)\left(\frac{b_{t-1}^{K}}{e_{t-1}}\right)\right], \text { if } \frac{b^{K}}{e} \leq\left(\frac{\gamma A}{\bar{r}-\phi}\right)^{\frac{1}{1-\gamma}}(\text { corner }) \\
(1-\alpha)(1-\gamma) A^{\frac{1}{1-\gamma}}\left(\frac{\gamma}{\bar{r}-\phi}\right)^{\frac{\gamma}{1-\gamma}}, \text { if } \frac{b^{K}}{e}>\left(\frac{\gamma A}{\bar{r}-\phi}\right)^{\frac{1}{1-\gamma}}(\text { interior })
\end{array}\right.
$$

\footnotetext{
${ }^{17}$ We assume that $\mathrm{A}$ is sufficiently large, i.e., $A \geq \frac{1}{[(1-\alpha)(\bar{r}-\phi)]^{1-\gamma}} \underline{A}(\phi)$, to ensure that worker income grows over time. Since $(1-\alpha)(\bar{r}-\phi)>1$, this is satisified if $A \geq \underline{A}(\phi)$.
} 
Equation (12) gives us the growth rate of education as a function of the capital education ratio. The possible scenarios of steady state growth are depicted in Figures 3a and 3b.

\section{Insert Figure 3A And Figure 3B Here.}

Figure 3a shows the steady state equilibrium when $A>\underline{A}(\phi)$. The growth rate of education is an increasing function of capital-education ratio. It reaches a maximum at $\frac{\widehat{b}}{e}$ after which it becomes constant as we have capital flight. The growth rate of capital is always equal to: $(1-\alpha)(\bar{r}-\phi)$. When $A>\underline{A}(\phi)$, these two curves intersect at a unique capital-education ratio, $\frac{\bar{b}}{e}$. If the initial ratio, $\frac{b_{0}}{e_{0}}<\frac{\bar{b}}{e}$, then the capital-education ratio, $\frac{b}{e}$, will increase. If $\frac{b_{0}}{e_{0}}>\frac{\bar{b}}{e}$, then the capital-education ratio, $\frac{b}{e}$, falls. This implies that the steady state equilibrium is unique and stable with both capital and education growing at the same rate. In the steady state, we always have a corner solution with no capital flight.

Figure 3b shows the steady state equilibrium when $A<\underline{A}(\phi)$. Irrespective of the initial capital education ratio, $\frac{b_{0}}{e_{0}}$, the growth rate of education never catches up with the growth rate of the capital stock. Eventually the domestic rental rate falls to a point where there is capital flight. This leads to unbalanced growth: i.e., to a situation in which $g_{K}>g_{e}$ in the steady state. If we interpret the $\frac{b}{e}$ ratio as a measure of inequality, then in steady state inequality keeps increasing. The income of the capitalists in comparison to the income of the workers also keeps increasing forever.

Proposition 2 suggests that capital controls are good for an economy when the level of technology is very low. However, when technology reaches a certain threshold capital controls can be harmful for growth. To see this intuitively, consider the case where $A>\underline{A}(\phi)$, under which the worker's optimal tax is a corner equilibrium (in terms of Figure $2 \mathrm{~b}$ ). When $\phi$ rises (capital controls rise) the worker's optimal tax on capital income increases. This lowers the after-tax income of capitalists in the next period and leads to lower domestic investment, $K$, as well as a reduction in the growth rate of capital, $g_{K}$. This reduces steady state wages and the income of workers, leading to lower investment in education. Therefore, a rise in $\phi$ leads to a lower capital-education ratio as well as lower equilibrium growth rates of education and capital. As such, a reduction in $\phi$ as long as $A>\underline{A}(\phi)$ facilitates the transition to the high equilibrium growth rate. This is because the level of technology is sufficient to sustain balanced growth, implying that developed countries do not require capital controls. This is consistent with recent evidence in Bekaert (2000) who show that while financial liberalizations are associated with significant increases in economic growth, the effect is larger for countries with high education levels.

When $A<\underline{A}(\phi)$, an interior equilibrium obtains and the optimal tax set by workers is zero. A rise in $\phi$ has two effects: first, it reduces capital flight which increases the domestic capital stock and 
wages, leading to higher income for the workers. This leads to more investment in education as well as a higher growth rate of education, $g_{e}$ (even though $g_{e}<g_{K}$ ). Figure 4 shows the effect of a change in $\phi$ on the $g_{K}$ and $g_{e}$ curves. Note that $\underline{A}(\phi)$ is falling in $\phi$. This implies that a rise in $\phi$ reduces the threshold required to jump to the balanced growth equilibrium. Increasing capital controls when a country is underdeveloped may be good, as it relaxes the constraint required to achieve the high growth equilibrium.

\section{Insert Figure 4 Here.}

Interestingly, in an interior equilibrium, the channel through which capital controls affects growth is not through the equilibrium tax rate. This is because the optimal taxes for workers are zero. A change in $\phi$ only affects the proportion of the capitalist's endowment invested domestically and abroad. This affects the wages of workers and their income which leads to changes in investment in education. Importantly, the channels through which changes in $\phi$ affect equilibrium growth depends on whether a corner or interior equilibrium obtains in steady state.

\section{$3.2 \theta<1$}

We now consider the case where human capital is concave with respect to investment in education i.e., $\theta<1$. The results are summarized by the following lemma.

Lemma 2 Given any initial endowment of capital, $b_{0}^{K}$, and education, $e_{0}$, there exists a time period $t^{\prime}$ such that $\widehat{r}_{t}<\bar{r}-\phi$ for all $t \geq t^{\prime}$.

Proof: We show that in the steady state there is some capital flight even if the economy starts off from a point where the domestic pre-tax rental rate exceeds the return from foreign investment for the capitalists. From equation (10), the evolution of education is given by

$$
e_{t}=(1-\alpha)\left[(1-\gamma)+\tau_{t} \gamma\right] A\left(b_{t-1}^{K}\right)^{\gamma}\left(e_{t-1}\right)^{\delta} \quad \text { if } \widehat{r}_{t}>\bar{r}-\phi
$$

From Proposition 1, we know that the optimal tax rate on rental income is given by, $\tau_{t}=1-\frac{\bar{r}-\phi}{r_{t}}$. Using (7) and (10), we can write the evolution of education as

$$
e_{t}=(1-\alpha)\left[A\left(b_{t-1}^{K}\right)^{\gamma}\left(e_{t-1}\right)^{\delta}-(\bar{r}-\phi) b_{t-1}^{K}\right]
$$

Accordingly, the growth rate of education is given by

$$
g_{e}=\frac{e_{t}}{e_{t-1}}=(1-\alpha)\left[A\left(\frac{b_{t-1}^{K}}{e_{t-1}}\right)^{\gamma} e_{t-1}^{(\theta-1)(1-\gamma)}-(\bar{r}-\phi)\left(\frac{b_{t-1}^{K}}{e_{t-1}}\right)\right] .
$$

When the growth rate of education, $g_{e}$, exceeds growth rate of domestic capital, $(1-\alpha)(\bar{r}-\phi)$, the capital-education ratio, $\frac{b^{K}}{e}$, falls in the next period. In addition, the term $e_{t-1}^{(\theta-1)(1-\gamma)} \rightarrow 0$ if 
$g_{e}>(1-\alpha)(\bar{r}-\phi)$. Hence, in the steady state, $g_{e}<(1-\alpha)(\bar{r}-\phi)$, which implies, $\widehat{r}_{t}=\gamma\left(\frac{e_{t-1}^{\theta}}{b_{t-1}^{K}}\right)^{1-\gamma}$, is monotonically decreasing over time. Hence, there exits a $t^{\prime}$ such that $\widehat{r}_{t}<\bar{r}-\phi$ for all $t \geq t^{\prime}$.

Lemma 2 says that irrespective of whether the initial world interest rate is less or greater than the initial domestic interest rate, an interior equilibrium obtains in the steady state in which optimal taxes are zero. Hence, when human capital is concave with respect to investment in education, an interior equilibrium obtains with a unique constant steady state level of education. In the next proposition, we characterize the unique steady state level of investment in education.

Proposition 3 In the steady state, the unique constant steady state level of education is given by,

$$
e^{*}=\left\{(1-\alpha)(1-\gamma) A^{\frac{1}{1-\gamma}}\left[\frac{\gamma}{\bar{r}-\phi}\right]^{\frac{\gamma}{1-\gamma}}\right\}^{\frac{1}{1-\theta}},
$$

and is independent of the initial endowments.

Proof: From Lemma 2, it follows that the economy eventually reaches a point when $\widehat{r}_{t}<\bar{r}-\phi$. From (10), the evolution of education is given by

$$
e_{t}=(1-\alpha)(1-\gamma) A^{\frac{1}{1-\gamma}}\left[\frac{\gamma}{\bar{r}-\phi}\right]^{\frac{\gamma}{1-\gamma}} e_{t-1}^{\theta}
$$

Education in period $t$ is a monotonically increasing concave function of the previous period's education. In the steady state, $e_{t}=e_{t-1}=e^{*}$. Hence, the steady state level of education is

$$
e^{*}=\left\{(1-\alpha)(1-\gamma) A^{\frac{1}{1-\gamma}}\left[\frac{\gamma}{\bar{r}-\phi}\right]^{\frac{\gamma}{1-\gamma}}\right\}^{\frac{1}{1-\theta}} .
$$

The intuition behind Proposition 3 operates similar to the case where $\theta=1$ and $A<\underline{A}(\phi)$ where a rise in $\phi$ induces a growth effect on the growth rate of education. Here a rise in $\phi$ has a level effect with the steady state equilibrium growth rate being zero. To see this, suppose there is an increase in $\phi$. Since the unique steady state equilibrium level of income is at an interior point, this implies that the optimal tax for workers is zero. ${ }^{18}$ Therefore, a rise in $\phi$ raises domestic investment, $K$, by the capitalists, and induces lesser capital flight. Since the domestic stock of capital increases, workers wage incomes increase leading to more investment in education. Hence, a higher $\phi$ - or more capital controls - lead to greater investment in education. Figure (5) depicts this. Starting at $e^{*}$, a higher $\phi$ moves the steady state to $e^{* *}$.

\section{INSERT FiguRE 5 HeRE.}

\footnotetext{
${ }^{18}$ In the steady state, the expression for worker's income is given by $y^{W}=w h=(1-\gamma)\left[\frac{\gamma}{\bar{r}-\phi}\right]^{\frac{\gamma}{1-\gamma}} e^{* \theta}$.
} 
Finally, our model can easily be extended to allow for the possibility of regime changes between the capitalists and workers. Consider the case where the workers have already set a tax rate, and a capitalist government comes to power. Suppose the capitalist government can change the capital control regime: i.e., set $\phi$, given $\tau$. From equation (9), we know that the workers set the tax rate such that the capitalist's make a return just equal to $\bar{r}-\phi$. This means that the capitalists are always better off by liberalizing the capital account: that is, set $\phi=0$. From Figure 5, we know that as $\phi$ falls, there is a sudden decline in investment in education, and the economy converges to a lower steady state equilibrium. This holds for both the case where $\theta<1$ as well as $\theta=1$ with $A<\underline{A}(\phi)$. Even in the case $\theta=1$ with $A<\underline{A}(\phi)$, a sufficiently large reduction in $\phi$ - because $\underline{A}(\phi)$ is decreasing in $\phi$ - would move the economy to an unbalanced growth equilibrium. Capital account liberalization yields the high growth equilibrium provided that the economy is sufficiently developed.

\section{The Model with Subsistence Production}

In this section we augment the model by introducing a subsistence production technology for the workers. The presence of a subsistence technology gives the workers an outside option similar to the outside option for capitalists, the return capitalists receive from investing abroad. We have seen in the previous section that income of the workers and human capital will have perpetual growth only when $\theta=1$. Since this is a more interesting case, we will assume that this condition holds.

At the end of each time period $t-1$, the government which is controlled by the workers announces a capital tax rate for period $t, \tau_{t}$. The workers and capitalists play a simultaneous move game where the workers choose how much of their bequest is to be invested in education while the capitalists decide how much to invest at home. We know that maximizing utility by workers and capitalists is equivalent to maximizing their income. In the presence of a subsistence technology a worker solves the following problem:

$$
\max _{e_{t-1}} y_{t}^{W}=w_{t} e_{t-1}+\tau_{t} r_{t} K_{t}+f\left(b_{t-1}^{W}-e_{t-1}\right),
$$

where $f($.$) denotes the subsistence sector technology, and \left(b_{t-1}^{W}-e_{t-1}\right)$ is the amount of workers' endowment invested in the subsistence sector. In the subsequent analysis we assume the following functional form for $f(.)^{19}$ :

$$
f\left(b_{t-1}^{W}-e_{t-1}\right)=\left(b_{t-1}^{W}-e_{t-1}\right)^{1-\gamma} .
$$

\footnotetext{
${ }^{19}$ The assumption of this functional form greatly simplifies the algebra and allows us to derive explict solutions for all the variables of interest. The results will hold qualitatively if the subsistence technology $f($.$) was increasing and concave$ in its argument.
} 
Maximizing (13) with respect to education implies

$$
w_{t}=(1-\gamma)\left(b_{t-1}^{W}-e_{t-1}\right)^{-\gamma}
$$

i.e., the workers invest in education until the returns from subsistence production equals the wage rate. Substituting for the wage rate gives us

$$
(1-\gamma) A K_{t}^{\gamma} e_{t-1}^{-\gamma}=(1-\gamma)\left(b_{t-1}^{W}-e_{t-1}\right)^{-\gamma}
$$

which after some manipulation can be written as,

$$
e_{t-1}=\left[\frac{A^{\frac{1}{\gamma}} K_{t}}{1+A^{\frac{1}{\gamma}} K_{t}}\right] b_{t-1}^{W} .
$$

Equation (15) denotes the reaction function of the workers. It tells us that as domestic investment by the capitalists increases, workers will invest more in education. The proportion of their bequest, $b_{t-1}^{W}$, invested in education is increasing in domestic investment level, $K_{t}$.

The problem faced by the capitalist is the same as before. The domestic investment by capitalists is given by

$$
K_{t}=\left\{\begin{array}{lr}
0 & \text { if } r_{t}\left(1-\tau_{t}\right)<\bar{r}-\phi \\
{\left[\frac{\left(1-\tau_{t}\right) \gamma A}{\bar{r}-\phi}\right]^{\frac{1}{1-\gamma}} e_{t-1}} & \text { if } r_{t}\left(1-\tau_{t}\right)=\bar{r}-\phi \\
b_{t-1}^{K} & \text { if } r_{t}\left(1-\tau_{t}\right)>\bar{r}-\phi
\end{array}\right.
$$

For any domestic investment to take place, the net domestic return, $r_{t}\left(1-\tau_{t}\right)$, must be sufficiently high. When $r_{t}\left(1-\tau_{t}\right)=\bar{r}-\phi$, domestic investment is increasing in education. As it turns out, this will be the only scenario we need to consider as the workers will always find it optimal to increase the tax rate on capital when, $r_{t}\left(1-\tau_{t}\right)>\bar{r}-\phi$, holds. This implies,

$$
K_{t}=\left[\frac{\left(1-\tau_{t}\right) \gamma A}{\bar{r}-\phi}\right]^{\frac{1}{1-\gamma}} e_{t-1},
$$

which we write as,

$$
e_{t-1}=\left[\frac{\bar{r}-\phi}{\left(1-\tau_{t}\right) \gamma A}\right]^{\frac{1}{1-\gamma}} K_{t} .
$$

Equation (17) is the reaction function of the capitalists. Figure 6 shows the reaction functions of the workers and the capitalists. The workers reaction function labeled as $W W$. It is increasing and concave in domestic capital, $K_{t}$. The capitalists reaction function is labeled as $K K$. It is linear and increasing until $K_{t}<b_{t-1}^{K}$, after which it becomes a vertical line. The intersection between these two 
curves gives us the equilibrium levels of domestic investment and education level in each time period $t$.

\section{Insert Figure 6 Here}

Let us denote the equilibrium domestic investment by $K_{t}^{*}$ and domestic education as $e_{t-1}^{*}$. Notice $K_{t}^{*}=0$ and $e_{t-1}^{*}=0$ is always a Nash equilibrium. However, the more interesting equilibrium is when the $K K$ and the $W W$ curves intersect at some $K_{t}^{*}>0$ and $e_{t-1}^{*}>0$. This equilibrium can be influenced by the tax rate set by the workers and the capital control regime in place.

Lemma 3 Let $B=\frac{\bar{r}-\phi}{\left(1-\tau_{t}\right) \gamma A}$. If $b_{t-1}^{W}<\frac{B^{\frac{1}{1-\gamma}}}{A^{\frac{1}{\gamma}}}$, then $K_{t}^{*}=0$ and $e_{t-1}^{*}=0$ is the only Nash equilibrium. Proof: Consider equation (15). Taking the derivative with respect to $K_{t}$ we get the slope of the workers reaction i.e.,

$$
\frac{d e_{t-1}}{d K_{t}}=\frac{b_{t-1}^{W} A^{\frac{1}{\gamma}}}{\left(1+A^{\frac{1}{\gamma}} K_{t}\right)^{2}}
$$

Note that $\frac{d e_{t-1}}{d K_{t}}$ is decreasing in $K_{t}$. As $K_{t} \rightarrow 0$ the slope of the workers reaction function reaches its maximum value $b_{t-1}^{W} A^{\frac{1}{\gamma}}$. The slope of the capitalists reaction function is given by $\left[\frac{\bar{r}-\phi}{\left(1-\tau_{t}\right) \gamma A}\right]^{\frac{1}{1-\gamma}}$,or, $B^{\frac{1}{1-\gamma}}$. Hence, if $b_{t-1}^{W} A^{\frac{1}{\gamma}}<B^{\frac{1}{1-\gamma}} \Longleftrightarrow b_{t-1}^{W}<\frac{B^{\frac{1}{1-\gamma}}}{A^{\frac{1}{\gamma}}}$, the only possible equilibrium is $K_{t}^{*}=0$ and $e_{t-1}^{*}=0$.

This is shown in Figure 7a when the $W W$ curve lies below the $K K$ curve. The entire endowment of the workers is invested in subsistence production while the capitalists invest their entire endowment abroad. The modern sector - corresponding to positive levels of education - in the economy does not exist. This gives us a lower bound on the workers endowment, i.e.,

$$
b_{t-1}^{W} \geq \underline{b}^{W}=\left[\frac{\bar{r}-\phi}{\gamma A}\right]^{\frac{1}{1-\gamma}}\left[\frac{1}{A}\right]^{\frac{1}{\gamma}}
$$

for the existence of the modern sector in the economy and the workers tax problem to be meaningful. Notice that the threshold $\underline{b}^{W}$ needed for the existence of the modern sector is increasing in $(\bar{r}-\phi)$ and decreasing in $A$. If, $b_{t-1}^{W} \geq \underline{b}^{W}$, there will be a Nash equilibrium where both $K_{t}^{*}$ and $e_{t-1}^{*}$ are positive. This is because higher capital controls leads to higher domestic investment leading to higher worker income, and subsequently higher investment in education by workers. Hence, higher capital controls make it possible for a modern sector to exist. In the next proposition, we characterize the levels of education investment and domestic investment that obtain in equilibrium.

\section{INSERT Figure 7A HeRE}


Proposition 4 If $b_{t-1}^{W}>\frac{B^{\frac{1}{1-\gamma}}}{A^{\frac{1}{\gamma}}}$, the equilibrium domestic capital and education are given by

$$
K_{t}^{*}=\min \left\{\frac{b_{t-1}^{W}}{B^{\frac{1}{1-\gamma}}}-\frac{1}{A^{\frac{1}{\gamma}}}, b_{t-1}^{K}\right\}, e_{t-1}^{*}=\min \left\{B^{\frac{1}{1-\gamma}} K_{t}^{*},\left(\frac{A^{\frac{1}{\gamma}} K_{t}^{*}}{1+A^{\frac{1}{\gamma}} K_{t}^{*}}\right) b_{t-1}^{W}\right\} \text {, }
$$

Proof: If $b_{t-1}^{W}>\frac{B^{\frac{1}{1-\gamma}}}{A^{\frac{1}{\gamma}}}$ we know that the slope of the workers reaction function will exceed the slope of the capitalists reaction function at $K_{t}=0$. Hence there will exist a unique Nash equilibrium where the $W W$ curve and $K K$ curves intersect. From equations (15) and (17) the equilibrium will be at a point when $\left[\frac{\bar{r}-\phi}{\left(1-\tau_{t}\right) \gamma A}\right]^{\frac{1}{1-\gamma}} K_{t}=\left[\frac{A^{\frac{1}{\gamma}} K_{t}}{1+A^{\frac{1}{\gamma}} K_{t}}\right] b_{t-1}^{W}$, or, $B^{\frac{1}{1-\gamma}} K_{t}=\left[\frac{A^{\frac{1}{\gamma}} K_{t}}{1+A^{\frac{1}{\gamma}} K_{t}}\right] b_{t-1}^{W}$. Solving for $K_{t}$ we obtain: $B^{\frac{1}{1-\gamma}}\left(1+A^{\frac{1}{\gamma}} K_{t}\right)=A^{\frac{1}{\gamma}} b_{t-1}^{W}$, or $B^{\frac{1}{1-\gamma}} A^{\frac{1}{\gamma}} K_{t}=A^{\frac{1}{\gamma}} b_{t-1}^{W}-B^{\frac{1}{1-\gamma}}$, or, $K_{t}^{*}=\frac{b_{t-1}^{W}}{B^{\frac{1}{1-\gamma}}}-\frac{1}{A^{\frac{1}{\gamma}}}$. Of course, $K_{t}^{*}$ cannot exceed $b_{t-1}^{K}$. Hence $K_{t}^{*}=\min \left\{\frac{b_{t-1}^{W}}{B^{\frac{1}{1-\gamma}}}-\frac{1}{A^{\frac{1}{\gamma}}}, b_{t-1}^{K}\right\}$. Substituting in equation (17) and (15)we have $e_{t-1}^{*}=\min \left\{B^{\frac{1}{1-\gamma}} K_{t}^{*},\left(\frac{A^{\frac{1}{\gamma}} K_{t}^{*}}{1+A^{\frac{1}{\gamma}} K_{t}^{*}}\right) b_{t-1}^{W}\right\}$.

The case where $K_{t}^{*}=b_{t-1}^{K}$ is depicted in Figure $7 \mathrm{~b}$.

\section{INSERT Figure 7B HeRE}

\subsection{Optimal Tax Rate under Subsistence Production}

We now characterize the optimal tax rate for the workers under subsistence production.

Proposition 5 Under subsistence production, the workers set a tax rate such that the capitalist is indifferent between investing at home or abroad. The optimal tax rate is given by,

$$
\tau_{t}=\left\{\begin{array}{cc}
0 \quad \text { if } K_{t}^{*}<b_{t-1}^{K} \\
\tau_{t}=1-\frac{\bar{r}-\phi}{\widehat{r}_{t}^{*}} & \text { if } K_{t}^{*}=b_{t-1}^{K}
\end{array}\right.
$$

where $K^{*}$ corresponds to the level of domestic investment under subsistence production, and $\widehat{r}_{t}^{*}$ corresponds to the domestic return to capital when the entire capitalist's endowment is invested domestically under subsistence production.

Proof: See Appendix 2.

Proposition 5 implies that the optimal tax rate under subsistence production is determined under a similar trade-off when workers do not invest in the subsistence technology in the previous section. Intuitively, since human capital and physical capital are complements, more of the former raises the return that capitalists receive from investing their endowment domestically. This lead to higher 
domestic investment. Therefore, in a corner equilibrium, the workers will tax capitalists up to an amount that keeps the capitalists indifferent between investing domestically and investing abroad. Given Proposition 5, we are now in a position to characterize the growth rates of the worker's and capitalists endowment.

The endowment of workers evolves according to,

$$
b_{t}^{W}=(1-\alpha) y_{t}^{W}
$$

When $K_{t}^{*}<b_{t-1}^{K}$,

$$
b_{t}^{W}=(1-\alpha)\left\{\frac{(1-\gamma) \gamma^{\frac{\gamma}{1-\gamma}} A^{\frac{1}{1-\gamma}} b_{t-1}^{W}}{(\bar{r}-\phi)^{\frac{\gamma}{1-\gamma}}}+\frac{\bar{r}-\phi}{A^{\frac{1}{\gamma}}}\right\} .
$$

With subsistence production the growth rate of workers endowment, $g_{W}$, is given by

$$
\frac{b_{t}^{W}}{b_{t-1}^{W}}=g_{W}=(1-\alpha)\left\{\frac{(1-\gamma) \gamma^{\frac{\gamma}{1-\gamma}} A^{\frac{1}{1-\gamma}}}{(\bar{r}-\phi)^{\frac{\gamma}{1-\gamma}}}+\frac{\bar{r}-\phi}{b_{t-1}^{W} A^{\frac{1}{\gamma}}}\right\} .
$$

In case $\widehat{r}_{t}^{*}>\bar{r}-\phi$ income of the workers is given by

$$
y_{t}^{W}=\left[(1-\gamma)+\tau_{t} \gamma\right] A\left(b_{t-1}^{K}\right)^{\gamma}\left(e_{t-1}^{*}\right)^{1-\gamma}+\left(\frac{e_{t-1}^{*}}{A^{\frac{1}{\gamma}} K_{t}}\right)^{1-\gamma}
$$

Substituting for $\tau_{t}$ and $\widehat{r}_{t}^{*}$ yields,

$$
y_{t}^{W}=A\left(b_{t-1}^{K}\right)^{\gamma}\left(e_{t-1}^{*}\right)^{1-\gamma}\left(\frac{1+A^{\frac{1}{\gamma}} b_{t-1}^{K}}{A^{\frac{1}{\gamma}} b_{t-1}^{K}}\right)-(\bar{r}-\phi) b_{t-1}^{K} .
$$

From (15) we know that

$$
e_{t-1}^{*}=\left[\frac{A^{\frac{1}{\gamma}} b_{t-1}^{K}}{1+A^{\frac{1}{\gamma}} b_{t-1}^{K}}\right] b_{t-1}^{W} \text {. }
$$

Hence,

$$
y_{t}^{W}=\left(b_{t-1}^{W}\right)^{1-\gamma}\left(1+A^{\frac{1}{\gamma}} b_{t-1}^{K}\right)^{\gamma}-(\bar{r}-\phi) b_{t-1}^{K} .
$$

The worker's endowment grows at the rate

$$
\frac{b_{t}^{W}}{b_{t-1}^{W}}=g_{W}=(1-\alpha)\left\{\left(\frac{1+A^{\frac{1}{\gamma}} b_{t-1}^{K}}{b_{t-1}^{W}}\right)^{\gamma}-(\bar{r}-\phi)\left(\frac{b_{t-1}^{K}}{b_{t-1}^{W}}\right)\right\} .
$$

The growth rate of capitalists endowment will remain the same as before i.e.,

$$
g_{K}=(1-\alpha)(\bar{r}-\phi)
$$


We have the growth rates for the worker's endowment when $K_{t}^{*}<b_{t-1}^{K}$ and $K_{t}^{*}=b_{t-1}^{K}$. We are now in a position to characterize which case will prevail in equilibrium. Note that,

$$
K_{t}^{*}<b_{t-1}^{K} \Longleftrightarrow \frac{b_{t-1}^{W}}{B^{\frac{1}{1-\gamma}}}-\frac{1}{A^{\frac{1}{\gamma}}}<b_{t-1}^{K} \Longleftrightarrow b_{t-1}^{W}<B^{\frac{1}{1-\gamma}} b_{t-1}^{K}+\frac{B^{\frac{1}{1-\gamma}}}{A^{\frac{1}{\gamma}}} .
$$

When $K_{t}^{*}<b_{t-1}^{K}$ we know that the tax rate is zero. Substituting for $B$ and using equation (18) we have

$$
\begin{aligned}
& b_{t-1}^{W}<\left(\frac{\bar{r}-\phi}{\gamma A}\right)^{\frac{1}{1-\gamma}} b_{t-1}^{K}+\left(\frac{\bar{r}-\phi}{\gamma A}\right)^{\frac{1}{1-\gamma}}\left(\frac{1}{A^{\frac{1}{\gamma}}}\right) \\
& b_{t-1}^{W}<\left(\frac{\bar{r}-\phi}{\gamma A}\right)^{\frac{1}{1-\gamma}} b_{t-1}^{K}+\underline{b}^{W} .
\end{aligned}
$$

This implies that when $b_{t-1}^{W}<\left(\frac{\bar{r}-\phi}{\gamma A}\right)^{\frac{1}{1-\gamma}} b_{t-1}^{K}+\underline{b}^{W}$ the growth rate of the worker's endowment will be given by equation (20)

$$
g_{W}=(1-\alpha)\left\{\frac{(1-\gamma) \gamma^{\frac{\gamma}{1-\gamma}} A^{\frac{1}{1-\gamma}}}{(\bar{r}-\phi)^{\frac{\gamma}{1-\gamma}}}+\frac{\bar{r}-\phi}{b_{t-1}^{W} A^{\frac{1}{\gamma}}}\right\} .
$$

When $b_{t-1}^{W} \geq\left(\frac{\bar{r}-\phi}{\gamma A}\right)^{\frac{1}{1-\gamma}} b_{t-1}^{K}+\underline{b}^{W}$, the growth rate is given by equation (22)

$$
g_{W}=(1-\alpha)\left\{\left(A^{\frac{1}{\gamma}} \frac{b_{t-1}^{K}}{b_{t-1}^{W}}+\frac{1}{b_{t-1}^{W}}\right)^{\gamma}-(\bar{r}-\phi)\left(\frac{b_{t-1}^{K}}{b_{t-1}^{W}}\right)\right\} .
$$

Note that $g_{W} \geq g_{e}$ irrespective of whether there is capital flight or not. This is because workers also invest in the subsistence technology. However, since the growth rate of education is greater than one, as $b_{t-1}^{W}$ becomes large $g_{W} \rightarrow g_{e}$. The growth rate of workers endowment and education are asymptotically the same (see equation 12),

$$
\begin{aligned}
& g_{W}=(1-\alpha)\left\{A\left(\frac{b_{t-1}^{K}}{b_{t-1}^{W}}\right)^{\gamma}-(\bar{r}-\phi)\left(\frac{b_{t-1}^{K}}{b_{t-1}^{W}}\right)\right\} \text { when } K_{t}^{*}=b_{t-1}^{K}, \\
& g_{W}=(1-\alpha)\left\{\frac{(1-\gamma) \gamma^{\frac{\gamma}{1-\gamma}} A^{\frac{1}{1-\gamma}}}{(\bar{r}-\phi)^{\frac{\gamma}{1-\gamma}}}\right\} \text { when } K_{t}^{*}<b_{t-1}^{K} .
\end{aligned}
$$

This is because as capital accumulation proceeds, the amount invested by workers in the subsistence technology diminishes. In the limit, workers spent their entire endowment on education with no investment in the subsistence technology. The growth rate of the worker's endowment also converges 
to the growth rate of education when $K$ is sufficiently large. This suggests that asymptotically, the economy with subsistence technology is identical to the economy where workers invest their entire endowment in education. The dynamics with subsistence technology are analogous to Figures $3 \mathrm{~b}$ and 4. By raising domestic investment, higher capital controls raise the growth rate of the worker's endowment, $g_{W}$, and reduce the worker's share of endowment invested in the subsistence technology. However, as in the earlier case, in an interior equilibrium with capital flight, the optimal taxes remain equal to zero. When the capitalists invest their entire endowment domestically, the tax rate on capital income will be positive, although the subsistence sector vanishes over time with sufficiently high growth in worker bequests.

\section{Conclusion}

This paper constructs a heterogenous agent OLG model to study the effect of the capital controls on the level of investment in human capital and the resulting growth path of an economy. The conventional wisdom in this literature says that reducing capital controls will curb the ability of the government to tax capitalists and therefore prove beneficial for growth. We find that it is indeed true but only when an economy is sufficiently developed and is able to sustain a balanced growth equilibrium in steady state. When an economy is underdeveloped and experiencing capital flight this argument does not apply. This result is consistent with a large literature on capital mobility and economic performance which suggests that an open capital account positively affects growth only after a country has achieved a certain degree of economic development (Edwards, 2000). Our results are also consistent with recent evidence in Bekaert et al. (2001) who show that while financial liberalizations are associated with significant increases in economic growth, the effect is larger for countries with high education levels. Finally, we also show that in an interior equilibrium, the capital control regime has no effect on the tax rates. Instead, they influence the equilibrium allocation of capital at home or abroad and as a result, investment in education. Higher capital controls in this environment can prevent excessive capital flight and help an economy to develop the modern sector. Higher capital controls also relax the constraint for the existence of balanced growth in a steady state equilibrium. 


\section{Appendix 1}

Consider the production function $Y=F(K, H)$ where $F($.$) is constant returns to scale in K$ and $H$. Since the indirect utility function of workers is monotonically increasing in the worker's income, $y_{t}^{W}=w_{t} H_{t}+\tau_{t} r_{t} K_{t}$, the tax rate that maximizes worker income also maximizes worker utility. Since the government is represented by the workers, the government solves

$$
\max _{\tau_{t}} y_{t}^{W}=w_{t} H_{t}+\tau_{t} r_{t} K_{t}
$$

subject to

$$
K_{t} \leq b_{t}^{K}
$$

and

$$
r_{t}\left(1-\tau_{t}\right) \geq \bar{r}-\phi
$$

If $K_{t} \leq b_{t}^{K}$ is binding at $\tau_{t}=0$, then $r_{t}\left(1-\tau_{t}\right)>\bar{r}-\phi$. In this case, the optimal tax rate is obtained from choosing the tax rate that solves, $r_{t}\left(1-\tau_{t}\right)=\bar{r}-\phi$. This corresponds to a corner equilibrium in which there is no capital flight and a positive tax rate. If $K_{t} \leq b_{t}^{K}$ is not binding at $\tau_{t}=0$, then $r_{t}\left(1-\tau_{t}\right) \geq \bar{r}-\phi$ holds with equality for all $\tau_{t} \in[0,1]$, i.e., $r_{t}\left(1-\tau_{t}\right)=\bar{r}-\phi$. This can be re-written as

$$
\tau_{t} r_{t} K_{t}=\left[r_{t}-(\bar{r}-\phi)\right] K_{t}
$$

Substituting the above expression into the objective function implies that,

$$
\begin{aligned}
y_{t}^{W} & =w_{t} H_{t}+\tau_{t} r_{t} K_{t} \\
& =w_{t} H_{t}+r_{t} K_{t}-(\bar{r}-\phi) K_{t}, \\
& =F\left(K_{t}, H_{t}\right)-(\bar{r}-\phi) K_{t} .
\end{aligned}
$$

Importantly, the expression, $F\left(K_{t}, H_{t}\right)-(\bar{r}-\phi) K_{t}$, reaches a maximum with respect to $K_{t}$ at the point

$$
F_{K}\left(K_{t}, H_{t}\right)=r_{t}=(\bar{r}-\phi)
$$


which implies a zero tax rate in equilibrium. This implies that the zero tax result is robust to any production function that is CRS in $K$ and $H$.

\section{Appendix 2}

Let us first consider the case $K_{t}^{*}<b_{t-1}^{K}$. We have already solved for the equilibrium domestic investment and education. Now we need to derive workers income at the equilibrium. Workers income in period $t$ is given by

$$
y_{t}^{W}=w_{t} e_{t-1}+\tau_{t} r_{t} K_{t}+\left(b_{t-1}^{W}-e_{t-1}\right)^{1-\gamma}
$$

From (14),

$$
A K_{t}^{\gamma} e_{t-1}^{-\gamma}=\left(b_{t-1}^{W}-e_{t-1}\right)^{-\gamma}
$$

which implies, $\left(b_{t-1}^{W}-e_{t-1}\right)=\frac{e_{t-1}}{A^{\frac{1}{\gamma}} K_{t}}$. We know that in equilibrium, $e_{t-1}^{*}=B^{\frac{1}{1-\gamma}} K_{t}^{*}$. This implies $\left(b_{t-1}^{W}-e_{t-1}^{*}\right)=\frac{B^{\frac{1}{1-\gamma}}}{A^{\frac{1}{\gamma}}}$. Hence, a workers income from the subsistence sector is given by, $\left(b_{t-1}^{W}-\right.$ $\left.e_{t-1}^{*}\right)^{1-\gamma}=\frac{B}{A^{\frac{1-\gamma}{\gamma}}}$. Now consider the expression: $w_{t} e_{t-1}+\tau_{t} r_{t} K_{t}=\left[(1-\gamma)+\tau_{t} \gamma\right] A K_{t}^{\gamma} e_{t-1}^{1-\gamma}=$ $\left[(1-\gamma)+\tau_{t} \gamma\right] A\left(K_{t}^{*}\right)^{\gamma}\left(B^{\frac{1}{1-\gamma}} K_{t}^{*}\right)^{1-\gamma}=\left[(1-\gamma)+\tau_{t} \gamma\right] A B K_{t}^{*}$. This allows us to write the workers total income as,

$$
y_{t}^{W}=\left[(1-\gamma)+\tau_{t} \gamma\right] A B K_{t}^{*}+\frac{B}{A^{\frac{1-\gamma}{\gamma}}} .
$$

Substituting for $K_{t}^{*}$ we have

$$
y_{t}^{W}=\left[(1-\gamma)+\tau_{t} \gamma\right] A B\left\{\frac{b_{t-1}^{W}}{B^{\frac{1}{1-\gamma}}}-\frac{1}{A^{\frac{1}{\gamma}}}\right\}+\frac{B}{A^{\frac{1-\gamma}{\gamma}}},
$$

which after substituting out for the term, $B$, and simplifying yields,

$$
y_{t}^{W}=\left[(1-\gamma)+\tau_{t} \gamma\right] \frac{A^{\frac{1}{1-\gamma}} b_{t-1}^{W}}{(\bar{r}-\phi)^{\frac{\gamma}{1-\gamma}}}\left[\left(1-\tau_{t}\right) \gamma\right]^{\frac{\gamma}{1-\gamma}}+\frac{\bar{r}-\phi}{A^{\frac{1}{\gamma}}} .
$$

Maximizing $y_{t}^{W}$ with respect to $\tau$ is equivalent to maximizing the expression $\left[(1-\gamma)+\tau_{t} \gamma\right][(1-$ $\left.\left.\tau_{t}\right) \gamma\right]^{\frac{\gamma}{1-\gamma}}$ with respect to $\tau$. We know from the proof of Proposition 1 that the tax rate which maximizes this expression is 0 . Hence the workers will set the capital tax rate equal to zero whenever there is capital flight in equilibrium i.e., $K_{t}^{*}<b_{t-1}^{K}$.

Like the previous section when $K_{t}^{*}=b_{t-1}^{K}$ the workers will set the tax rate on capital so that the capitalists are just indifferent between investing at home or abroad. Recall our previous definition of 
$\widehat{r}_{t}=\gamma A\left(\frac{e_{t-1}}{b_{t-1}^{K}}\right)^{1-\gamma}$. With the presence of the subsistence sector $e_{t-1}$ is not equal to $b_{t-1}^{W}$ but a function of $b_{t-1}^{W}$ and $K_{t}^{*}$. Define $\widehat{r}_{t}^{*}$ as the equilibrium interest rate i.e.,

$$
\widehat{r}_{t}^{*}=\gamma A\left(\frac{e_{t-1}^{*}}{K_{t}^{*}}\right)^{1-\gamma}
$$

At the equilibrium $K_{t}^{*}=b_{t-1}^{K}$ only if $\widehat{r}_{t}^{*}>\bar{r}-\phi$. Hence, the tax rate set by the workers will be

$$
\tau_{t}=1-\frac{\bar{r}-\phi}{\widehat{r}_{t}^{*}}>0
$$




\section{References}

[1] Aguiar, Mark, Manuel Amador, and Gita Gopinath, 2005, Efficient Fiscal Policy and Amplification, Mimeo, University of Chicago, Chicago, USA.

[2] Alesina, Alberto and Dani Rodrik, 1994, Distributive Politics and Economic Growth, Quarterly Journal of Economics, Vol. 109, May, 465-90.

[3] Alesina, Alberto and Guido Tabellini, 1989, External Debt, Capital Flight and Political Risk," Journal of International Economics, November, 27:199-220

[4] Alfaro, Laura and Fabio Kanczuk, 2004, Capital Controls, Risk, and Liberalization Cycles, Review of International Economics, Vol. 12, 412-434.

[5] Bekaert, Geert, Campbell Harvey, and Christian Lundblad, 2001, Emerging Equity Markets and Economic Development, Journal of Development Economics, Vol. 66, 465-504.

[6] Bils, Mark and Peter Klenow, Does Schooling Cause Growth?, 2000, American Economic Review, Vol. 90, 1160-1183.

[7] Bourguignon, Francois \& Verdier, Thierry, 2000a, Oligarchy, democracy, inequality and growth, Journal of Development Economics, vol. 62(2), pages 285-313

[8] Bourguignon, Francois and Thierry Verdier, 2000b, Is Financial Openness Bad for Education? A Political Economy Perspective on Development, European Economic Review, Vol. 44, 891-903.

[9] Bourguignon, Francois and Thierry Verdier, 2005, The Political Economy of Education and Development in an Open Economy, Review of International Economics, Vol. 13, 529 - 548.

[10] Caselli, Francesco and James Feyrer, 2005, The Marginal Product of Capital, NBER Working Paper 11551, Cambridge, MA.

[11] Collier, Paul, Anke Hoffler, and Catherine Patillo, 2001, Flight Capital as Portfolio Choice, The World Bank Economic Review, Vol. 15, p. 55 - 80.

[12] Collier, Paul, Anke Hoffler, and Catherine Patillo, 2004, Africa's Exodus: Capital Flight and the Brain Drain as Portfolio Decisions, Journal of African Economies, Vol. 13, p. ii15 - ii54. 
[13] Das, Satya, and Chetan Ghate, 2004, Endogenous Distribution, Politics, and the Growth Equity Trade-off, Contributions to Macroeconomics, Vol. 4, Article 6, Berkeley Electronic Press.

[14] Edwards, Sebastian, 2000, Capital Mobility and Economic Performance: Are Emerging Economies different? Mimeo, UCLA.

[15] Galor, Oded and Omer Moav, 2004, From Physical to Human Capital Accumulation: Inequality in the Process of Development, Review of Economic Studies, Vol. 71, 1001-1026

[16] Galor, Oded and Omer Moav, 2006, Das Human-Kapital: A Theory of the Demise of the Class Structure, The Review of Economic Studies, Volume 73, Number 1 (January), pp. 85-117

[17] Gournichas, Olivier-Pierre, and Olivier Jeanne, 2003, The Elusive Gains from International Financial Integration, NBER Working Paper, 9684.

[18] Glaeser, Edward L, 2005, Inequality, Harvard Institute of Economic Research, Discussion Paper no 2078, Harvard University, Cambridge, Mass.

[19] Hall, Robert, and Charles Jones, 1999, Why do some Countries produce more Output than Others ? Quarterly Journal of Economics, Vol. 114 (February), 83-116.

[20] Manuelli, Rodolfo and Ananth Seshadri, 2005, Human Capital and the Wealth of Nations, University of Wisconsin-Madison, mimeo.

[21] Mourmouras, Alex and Peter Rangazas, 2005, Evaluating Conditional Aid Policies, Mimeo, IUPUI, Indianapolis, Indiana, USA.

[22] Perotti, Roberto, 1996, Growth, Income Distribution, and Democracy: What the Data Say, Journal of Economic Growth, Vol. 1, June, 149-87.

[23] Quadrini, Vincenzo, 2005, Policy Commitment and the Welfare Gains from Capital Market Liberalization, European Economic Review, Vol. 49, 1927-1951

[24] Saint-Paul, Gilles and Thierry Verdier, 1993, Education, Democracy and Growth, Journal of Development Economics, Vol. 42, December, 399-407

[25] Viaene, Jean Marie and Itzhak Zilcha, 2002(a), Capital Markets Integration, Growth and Income Distribution, European Economic Review, Vol. 46, 301-327. 
[26] Viaene, Jean Marie and Itzhak Zilcha, 2002(b), Public Education Under Capital Mobility, Journal of Economic Dynamics and Control, Vol. 26, 2005-2036. 


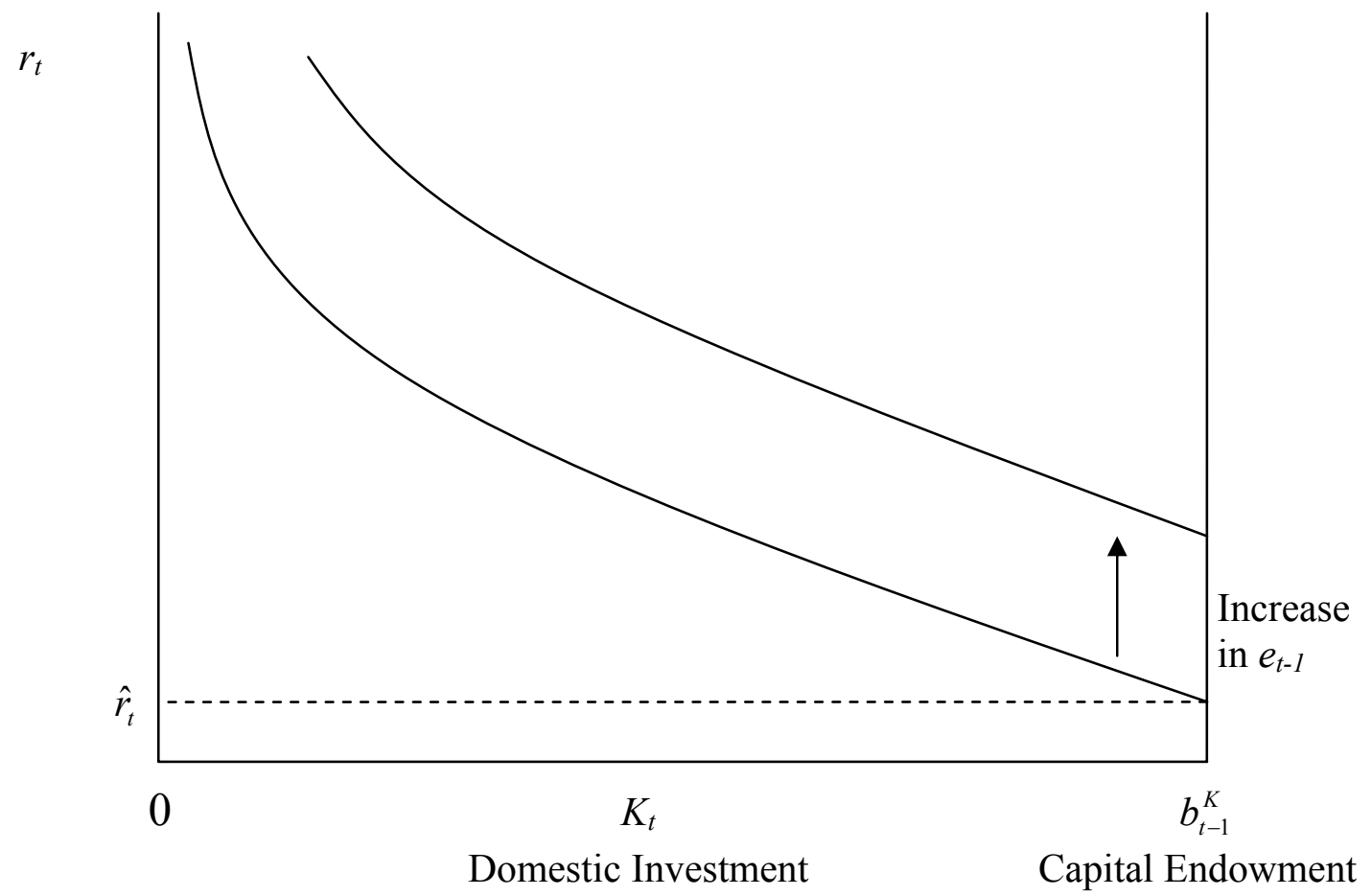

Figure 1: Pre-tax rental rate and $\hat{r}_{t}$

$$
\begin{aligned}
& r_{t}=\gamma A\left(\frac{e_{t-1}^{\theta}}{K_{t}}\right)^{1-\gamma} \\
& \hat{r}_{t}=\gamma A\left(\frac{e_{t-1}^{\theta}}{b_{t-1}^{K}}\right)^{1-\gamma}
\end{aligned}
$$




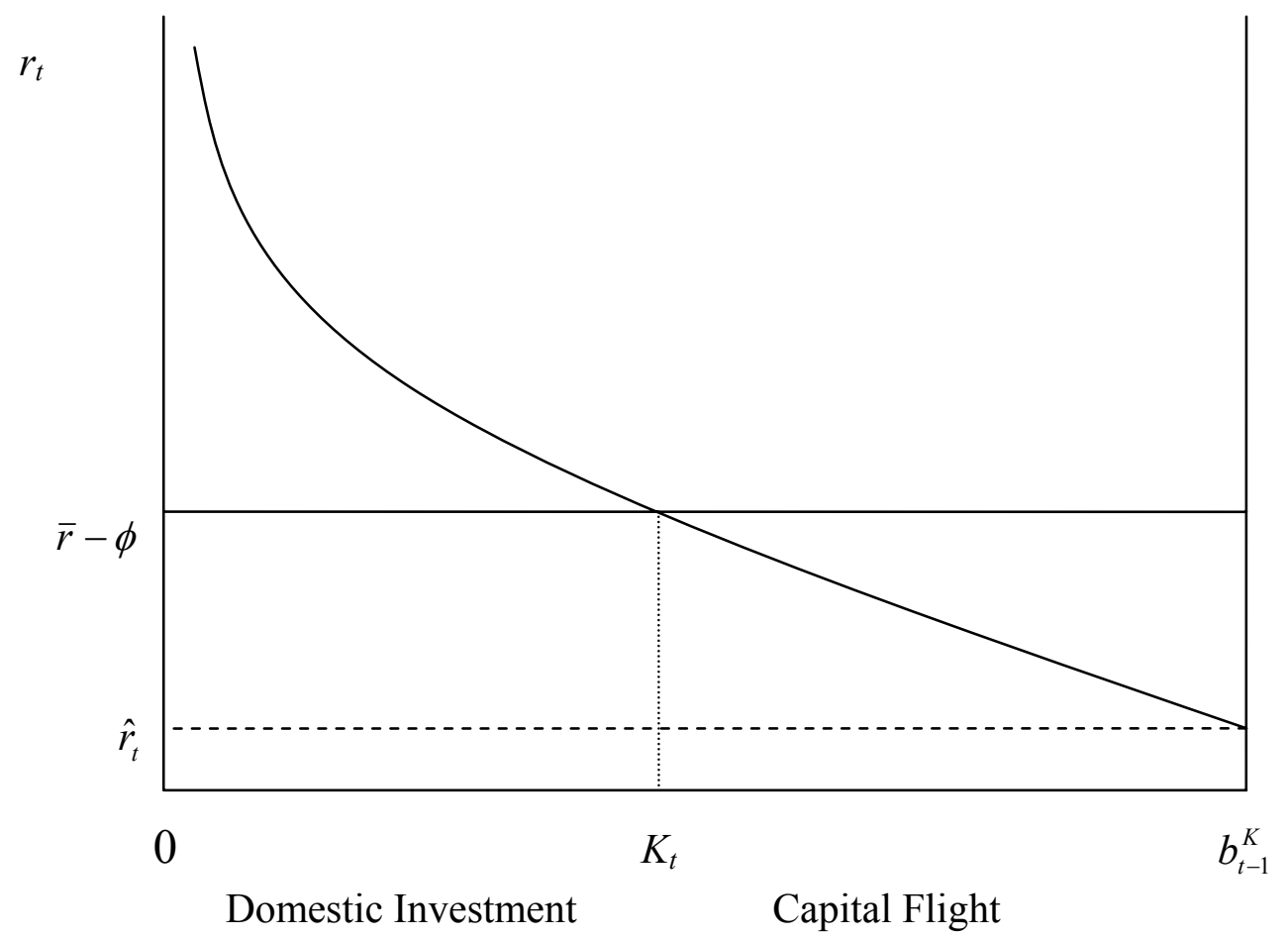

Figure 2a: $\hat{r}_{t}<\bar{r}-\phi$ 


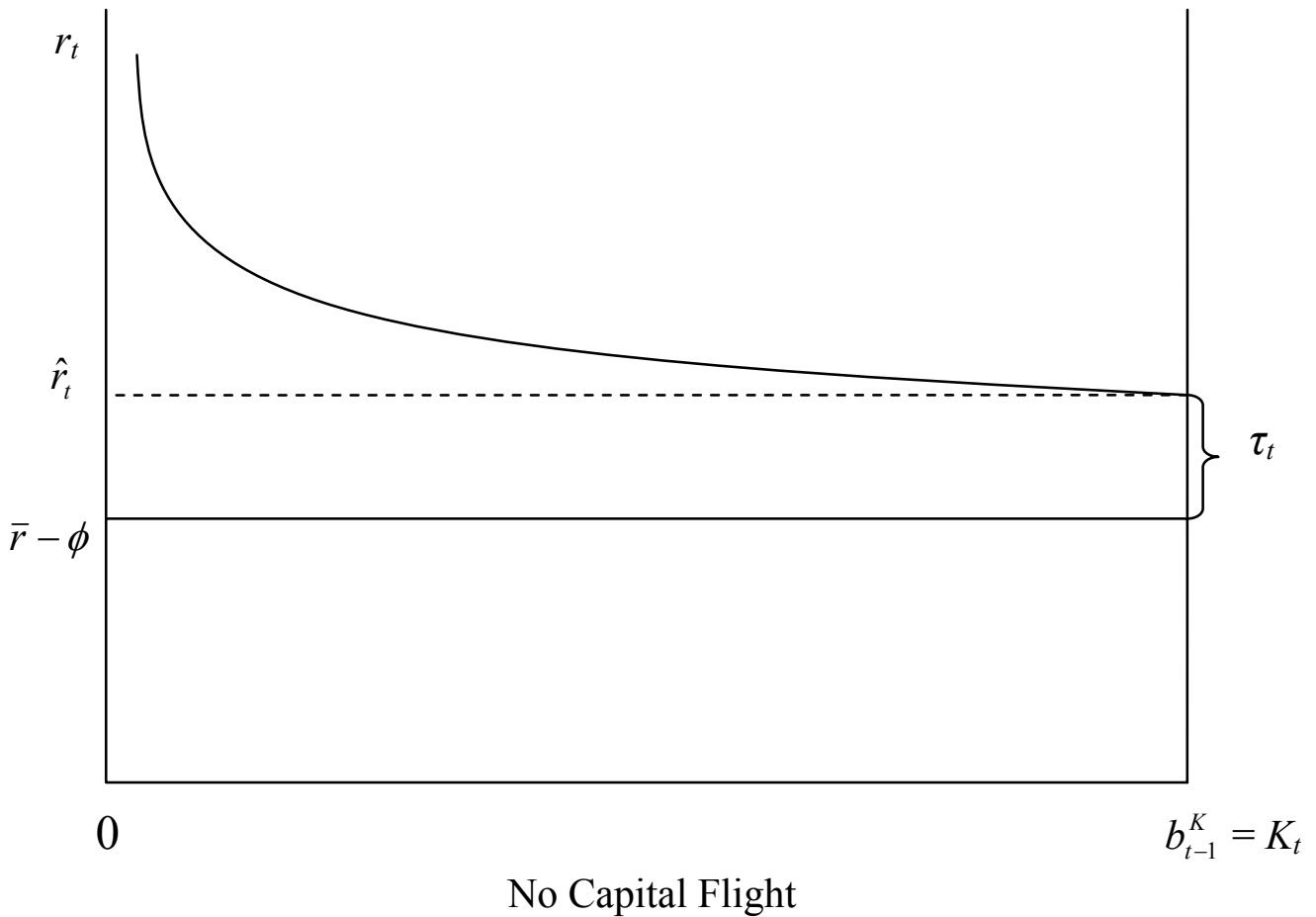

Figure 2b: $\hat{r}_{t}>\bar{r}-\phi$ 


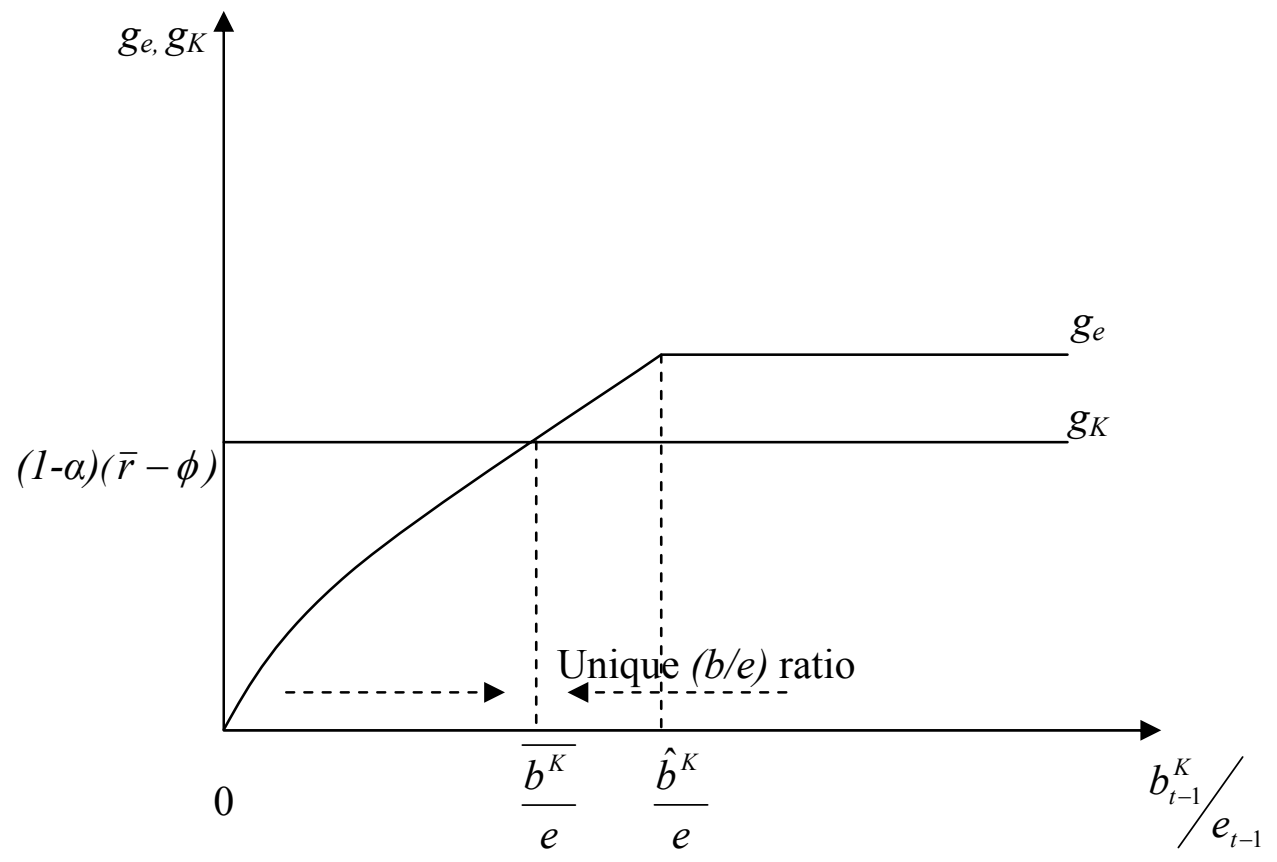

Figure 3a: Steady State with $\theta=1$

$$
A>\underline{A}(\phi)
$$




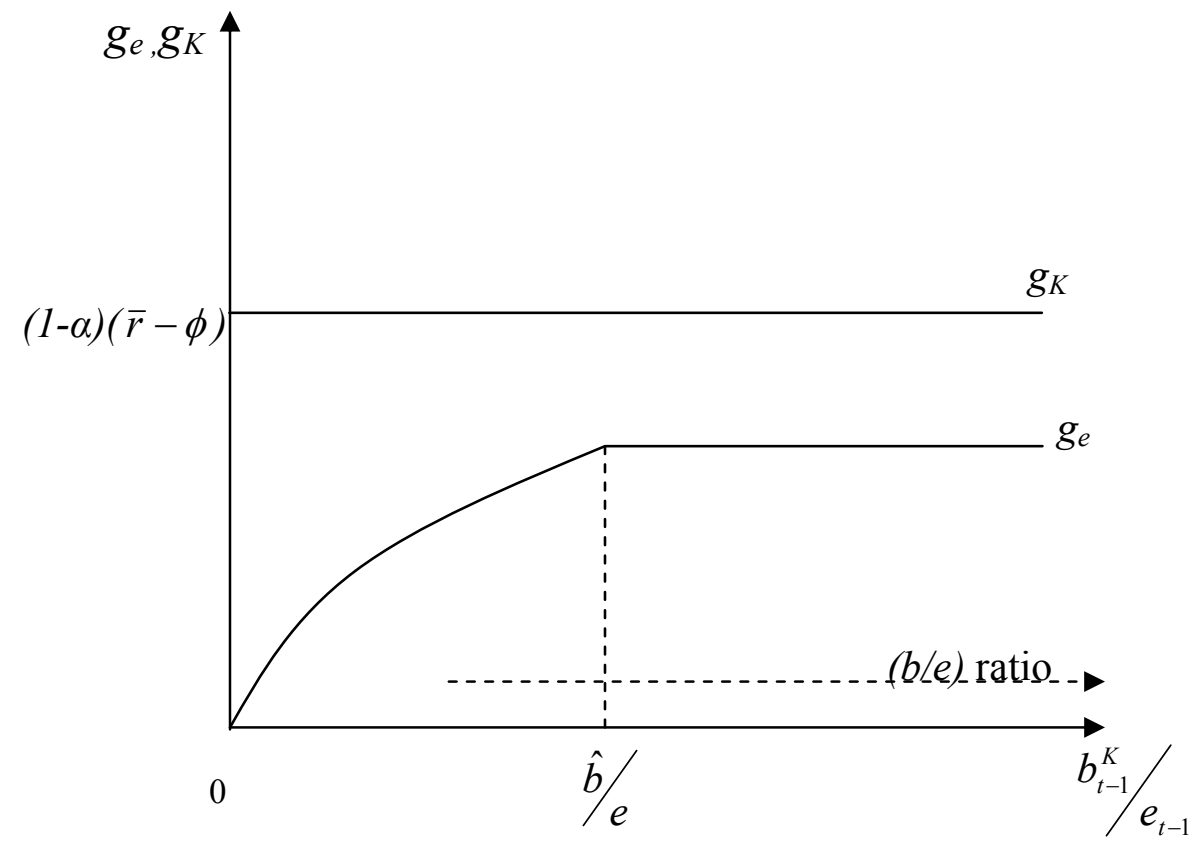

Figure 3b: Steady State with $\theta=1$

$A<\underline{A}(\phi)$ 


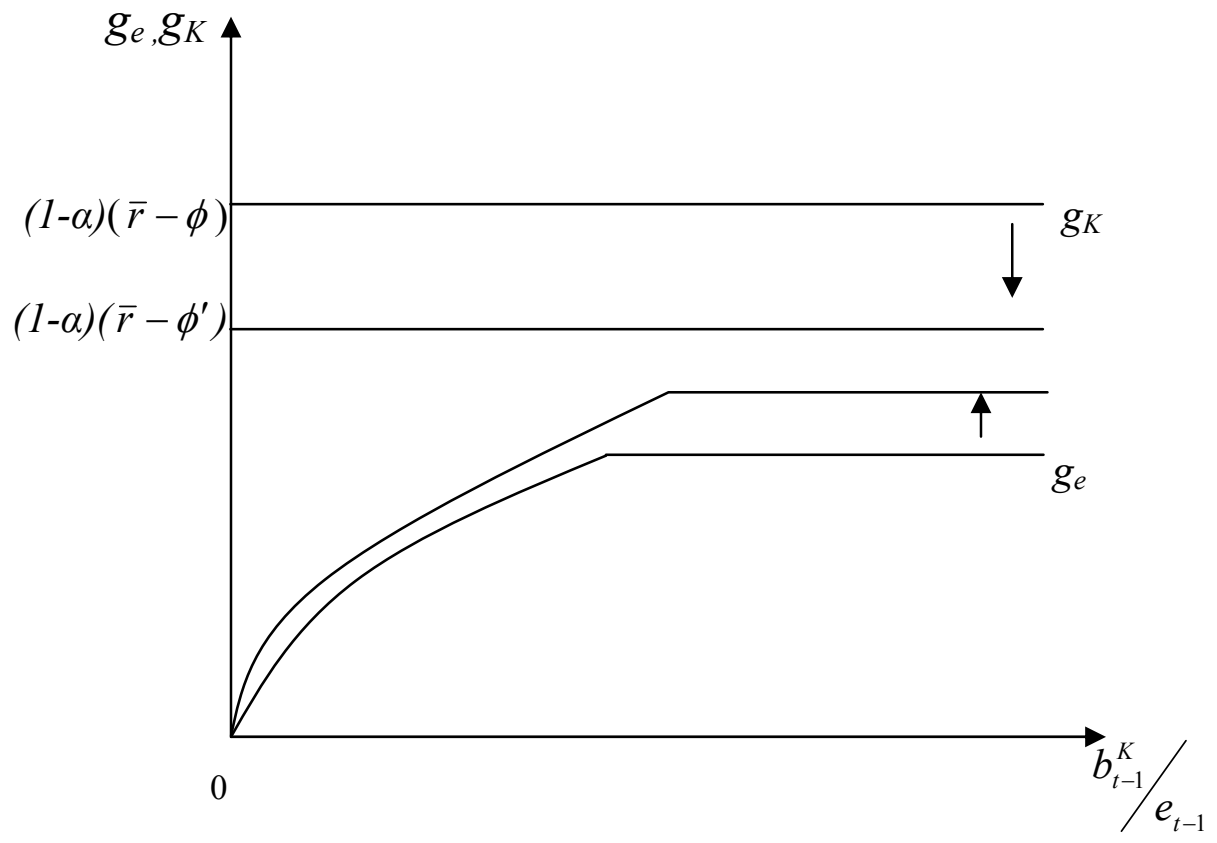

Figure 4: Change in Capital Controls $\phi^{\prime}>\phi$ $A<\underline{A}(\phi)$ 


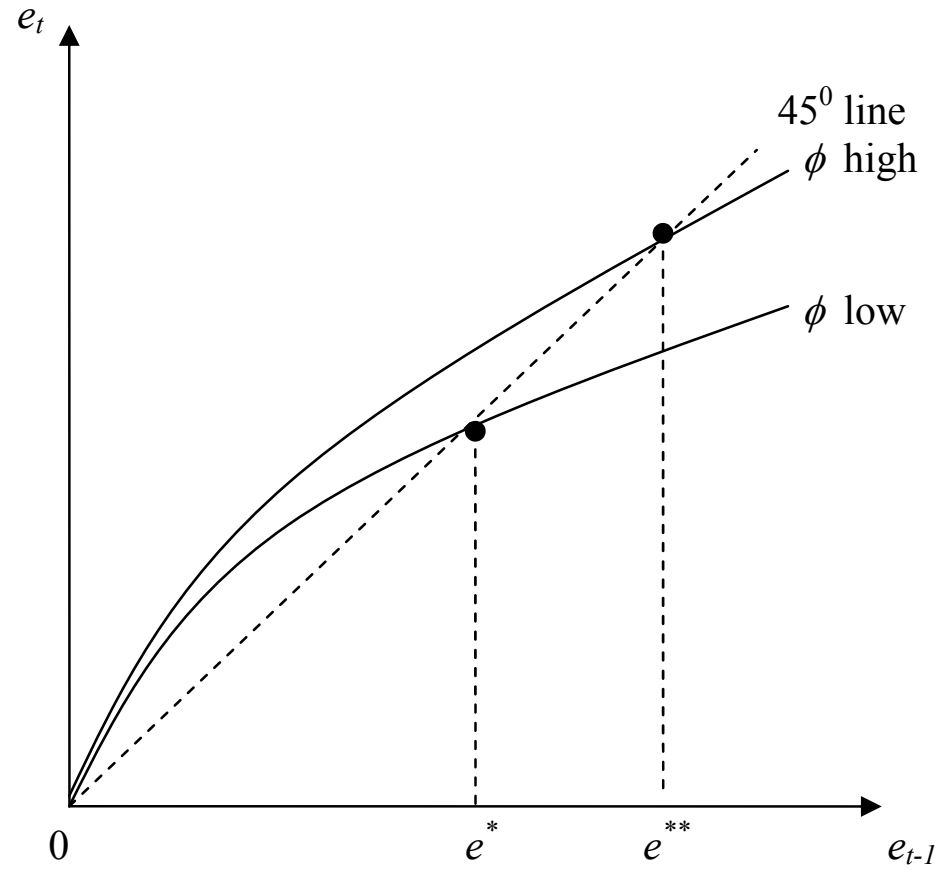

Figure 5: Steady State with $\theta<1$ 


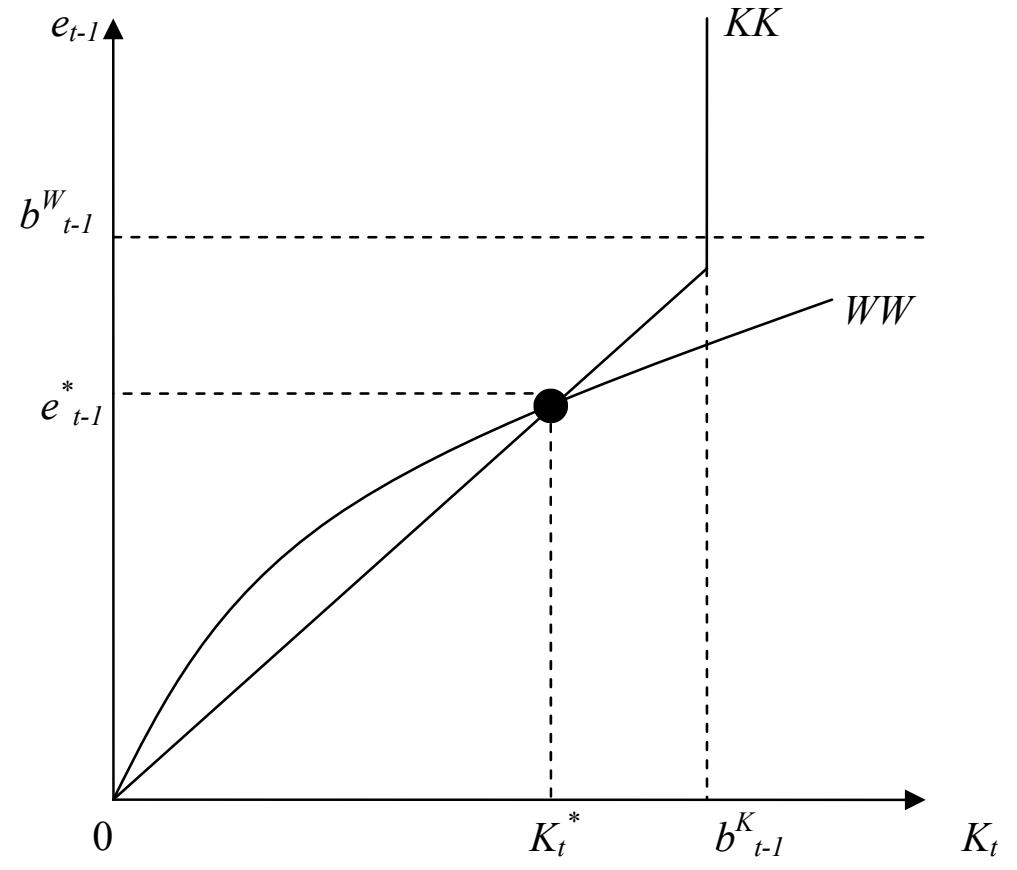

Figure 6: Reaction Functions

$$
e^{*}{ }_{t-1}<b^{W}{ }_{t-1}, K_{t}^{*}<b^{K}{ }_{t-1}
$$




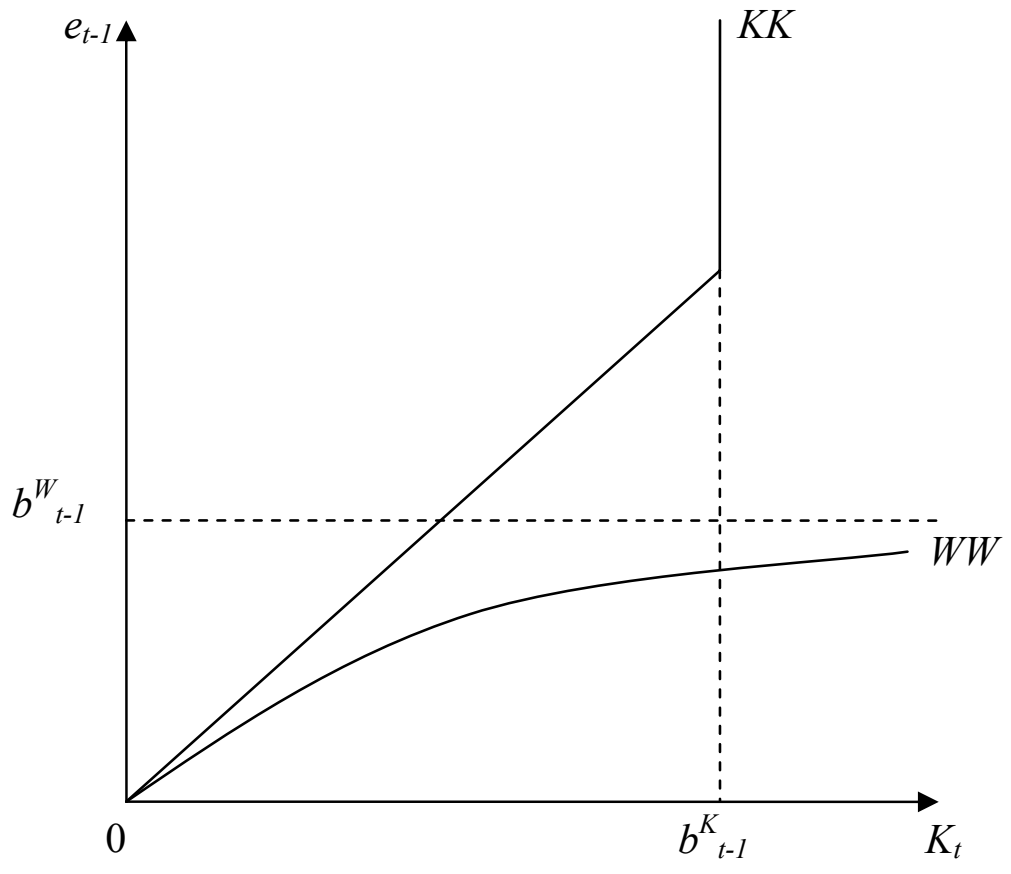

Figure 7a: No Modern Sector $e^{*}{ }_{t-1}=0, K_{t}^{*}=0$ 


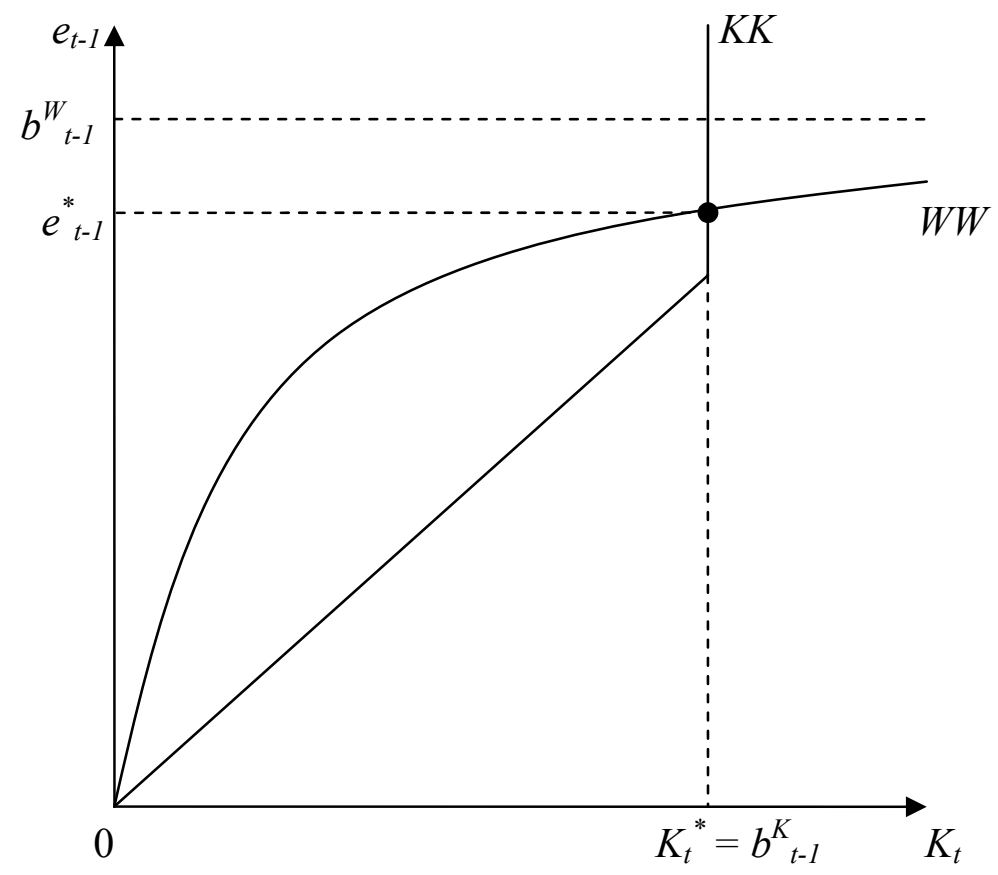

Figure 7b: Positive Taxes

$e_{t-1}^{*}<b_{t-1}^{W}, K_{t}^{*}=b_{t-1}^{K}$ 